\title{
On the robustness of ENSO teleconnections
}

\author{
Andreas Sterl · Geert Jan van Oldenborgh • \\ Wilco Hazeleger · Gerrit Burgers
}

Received: 20 May 2006/Accepted: 21 March 2007/Published online: 21 April 2007

(C) Springer-Verlag 2007

\begin{abstract}
Using observations covering the last 128 years we show that apparent changes in El Niño-Southern Oscillation (ENSO) teleconnections can be explained by chance and stem from sampling variability. This result is backed by experiments in which an atmosphere model is driven by 123 years of observed sea surface temperature. The possibility of ENSO teleconnection changes in a warming climate is further investigated using coupled GCMs driven by past and projected future greenhouse gas concentrations. These runs do not exclude physical changes in the teleconnection strength but do not agree on their magnitude and location. If existing at all, changes in the strength of ENSO teleconnection, other than obtained by chance, are small and will only be detectable on centennial time scales.
\end{abstract}

\section{Introduction}

El Niño-Southern Oscillation (ENSO) is the largest climate signal on interannual time scales. During an El Niño event the eastern half of the equatorial Pacific Ocean warms significantly, reaching sea surface temperature (SST) anomalies that can exceed $3 \mathrm{~K}$ over large areas. The anomalous warming triggers changes in the atmospheric circulation far away from the forcing region (see Sect. 2.1). These teleconnections have been known for a long time

A. Sterl ( $\bowtie)$ . G. J. van Oldenborgh · W. Hazeleger ·

G. Burgers

Royal Netherlands Meteorological Institute (KNMI),

P.O. Box 201, 3730 AE De Bilt, Netherlands

e-mail: sterl@knmi.nl (e.g., Walker 1925; Berlage 1957) and can be dynamically explained by Rossby wave propagation driven by an anomalous heat source (e.g., Hoskins and Karoly 1981). A convenient measure of ENSO is the NINO3.4 index $\left(\mathrm{N}_{34}\right)$, defined as the anomaly of SST averaged over the NINO3.4 region $17^{\circ} \mathrm{E}-120^{\circ} \mathrm{W}, 5^{\circ} \mathrm{S}-5^{\circ} \mathrm{N}$, and the strength of an ENSO teleconnection is defined as the linear regression coefficient of the atmospheric field in question (e.g., sea level pressure) on $\mathrm{N}_{34}$ (see Sect. 2.1 for more details).

Teleconnections are important for several reasons. First, projected changes in ENSO properties can influence the climate in areas far away from the Pacific. Second, given the potential predictability and long decay time of ENSO SST anomalies, they can be exploited to make climate forecasts on a seasonal or even annual time scale. Third, they can be used to reconstruct past ENSO variability from climate proxy data or, vice versa, to infer circulation anomalies from known ENSO variability. These applications rely on the stationarity of the teleconnections, i.e., the stationarity of the regression time series, implicitly assuming that the teleconnection strength does not change significantly with time.

However, the atmospheric circulation is not solely determined by ENSO, but also by processes that are independent of ENSO and have different time scales. For short periods, the measured regression between ENSO and the atmospheric circulation depends on the realization of these processes, and therefore observed teleconnections do show changes in strength over time. The question then arises whether these observed changes are significant, reflecting a change in the physics of the climate system, or whether they can be explained by chance, arising from differences in the realization of short-term processes not related to ENSO. Mathematically, the question is whether the regression time series is stationary or not. 
Fogt and Bromwich (2006) provide an example for a situation in which non-ENSO influences cause a change in the strength of the ENSO teleconnection. They investigate the correlation between ENSO and atmospheric pressure in the south-east Pacific (west of Drake Passage) and find significant differences between the 1980s and the 1990s. They explain their finding by the fact that this region is not only influenced by ENSO, but also by the Southern Annular Mode (SAM), a nearly zonally symmetric contraction and expansion of the polar vortex. Depending on whether the effects of ENSO and SAM reinforce or oppose each other in this region the correlation of pressure with ENSO changes. Fogt and Bromwich (2006) only analyze 20 years of data. This is much too short to decide whether the difference found between the 1980s and the 1990s results from a change in physics or from an accidental change in the relative phases of ENSO and SAM.

A situation in which a change in physics leads to a change in the strength of a teleconnection is presented by Timm et al. (2005). They suggest that a change in mean SST over the Indian Ocean during the 1970s moved the system closer to the deep convection limit of $28.5^{\circ} \mathrm{C}$. SST anomalies of a given magnitude would then be more likely to trigger deep convection than before, resulting in a closer relationship between SST anomalies and convection-triggered teleconnections.

The characteristics of ENSO and its evolution have changed around 1976 as part of the well-known regime shift that affected the whole Pacific basin (e.g., Wang and An 2001), and changes in the ENSO teleconnections around that year have been noted (e.g., Trenberth et al. 2002), suggesting a physical mechanism (cause-effect relation) for the change. On the other hand Gershunow et al. (2001) analyzed the relationship between ENSO and All Indian Rainfall (AIR). Correlation coefficients between an ENSO index and AIR, calculated over different 21-year periods, were found to vary between -0.47 and -0.78 . While it is tempting to try to ascribe such large changes to some physical changes in the climate system, Gershunov et al. (2001) show that two white noise processes can display the same or even a larger variation in correlation. In this paper we extend the analysis of Gershunov et al. (2001) to the relation between ENSO and the global atmospheric circulation, represented by surface pressure (SLP) and $500 \mathrm{hPa}$ height $\left(z_{500}\right)$.

The question whether observed changes in teleconnection strength are significant or can be attributed to chance was further investigated in a paper by Van Oldenborgh and Burgers (2005). Applying a method based on Gershunov et al. (2001) to data from 568 precipitation stations they found that the number of stations showing a statistically significant change of their teleconnections to ENSO was about equal to the number to be expected from pure chance. Furthermore, stations with a statistically significant change were often not neighboured by other stations with a significant change. Their conclusion therefore was that observed changes in the strength of the ENSO-to-precipitation teleconnections mainly occurred by chance and were not driven by changes in the underlying physics.

Precipitation is a noisy variable, with small-scale variations and relatively weak teleconnections. Changes in the strength of teleconnections show up more clearly in smoother variables with less noise. In this paper we therefore apply the method of Van Oldenborgh and Burgers (2005) to modelled and observed data of sea level pressure and $500 \mathrm{hPa}$ height. Modelled data come from an Atmosphere General Circulation Model (AGCM) driven by historic SST data and from coupled climate models driven by observed and projected concentrations of greenhouse gases. The models have been run in ensemble mode, increasing the statistical robustness of the results. The combined use of observed data and those modelled for past and projected future climate conditions allows the following questions to be addressed:

- Do observations suggest significant low-frequency temporal changes in teleconnection strength, i.e., changes brought about by changes in ENSO physics rather than by chance? Or: Are ENSO teleconnections stationary?

- Are these results backed by model results?

- Will teleconnection strengths change under global warming?

The last question has been addressed by Meehl et al. (2006) and by Müller and Roeckner (2006). The first authors find weaker teleconnections in a future, warmer, climate, while the latter find stronger ones. However, both of them do not use regression to measure the strength of a teleconnection, but the magnitude of the atmospheric response to a strong ENSO event. A strong ENSO event is defined as $\mathrm{N}_{34}$ exceeding one standard deviation. In the models analyzed by Meehl et al. (2006) ENSO variability decreases, so strong ENSOs become weaker, while the opposite is true for the model used by Müller and Roeckner (2006). Therefore, the results of both groups could be compatible with a stationary regression: Larger (weaker) ENSO events cause a larger (weaker) atmospheric response. In other words, not the strength of the teleconnections changes, but the driving force (ENSO) does.

ESNO response is known to be nonlinear (e.g., Hoerling et al. 1997), meaning that the response to a strong ENSO event is relatively larger than that to a weak event. Furthermore, there is evidence for ENSO development to have changed (e.g., Wang and An 2001), implying possible changes in lagged relations. The same technique as used in this paper can be used to investigate whether or not the 
nonlinear response or the lagged response are stationary. However, the nonlinear response is small and mainly confined to an area around the intersection of data line and equator and to the Great Plains of North America. Furthermore, the applications mentioned above usually only use the linear response to ENSO. We therefore confine ourselves to the linear ENSO response. Restriction to zero lag arises from the short adjustment time of the atmosphere of 2 weeks or so. Teleconnections show up quickly and, using monthly means, their main characteristics are captured at zero lag.

\section{Method and data}

\subsection{Method}

For convenience we start with an explanation of the method proposed by Van Oldenborgh and Burgers (2005) to investigate the robustness of observed teleconnection changes. It is based on the stationarity test of Gershunov et al. (2001), who showed that stochastic fluctuations can lead to large variations in correlations between two time series.

a) Hadley (1871-1998)

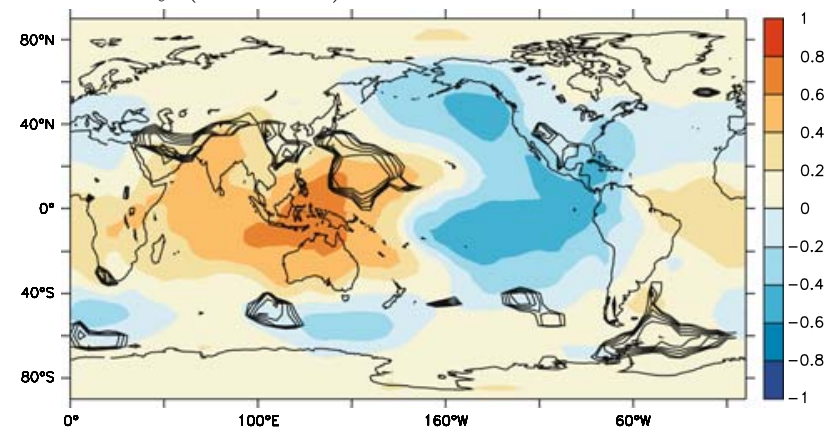

c) Speedy $(1881-2002)$

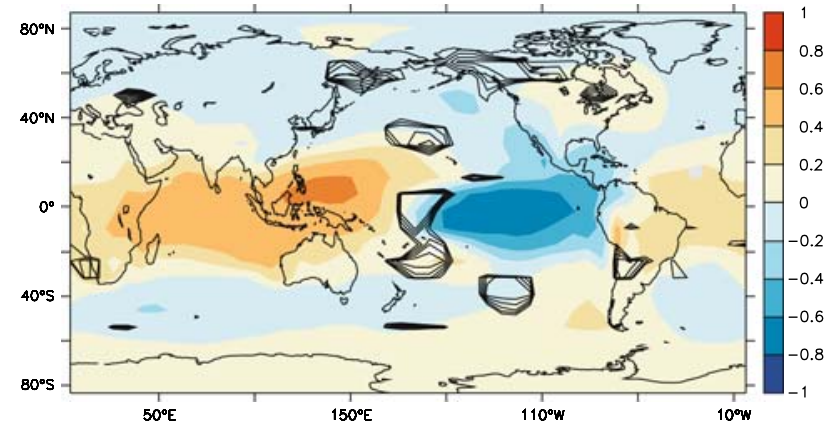

Fig. 1 Correlation between the NINO3.4 index and SLP in January for a observations (HadSLP1/HadISST_1_1), b reanalysis (ERA-40), c Speedy, and d ECHAM5/MPI-OM. Model results are for the whole ensemble (all members together), and only the historical period (before 2000) is used for (c) and (d) for better comparison with (a)
Correlation and (linear) regression are used to identify and visualize teleconnections. Their definitions and main properties are given in the Appendix. Correlating the NINO3.4 index with anomalies of, for instance, sea level pressure (SLP or $p$ ) gives characteristic patterns of high and low correlations. As Fig. 1 shows, ENSO systematically influences the atmospheric circulation even in areas far away from the NINO3.4 region. The strength of a teleconnection is measured by the linear regression of SLP on $\mathrm{N}_{34}$. Figure 2 shows the regression of SLP on $\mathrm{N}_{34}$ for the same datasets that were used in Fig. 1 for correlation. The dimension is $\mathrm{hPa} / \mathrm{K}$, which implies that SLP decreases by up to $3.75 \mathrm{hPa}$ in the northern North Pacific if the NINO3.4 region warms by $1 \mathrm{~K}$.

As the SLP anomaly at a given place is partly influenced by ENSO we can imagine it to be composed of two parts, one directly related to ENSO and the other one unrelated:

$$
\begin{aligned}
p(t) & =r \mathrm{~N}_{34}(t)+\left[p(t)-r \mathrm{~N}_{34}(t)\right] \\
& =r \mathrm{~N}_{34}(t)+\sigma_{p} \sqrt{1-c^{2}} \eta(t) .
\end{aligned}
$$

In this equation $r=\operatorname{regr}\left(\mathrm{N}_{34}, p\right)$ and $c=\operatorname{corr}\left(\mathrm{N}_{34}, p\right)$ are respectively the observed regression and correlation be-

b) $\mathrm{ERA}-40(1957-2002)$

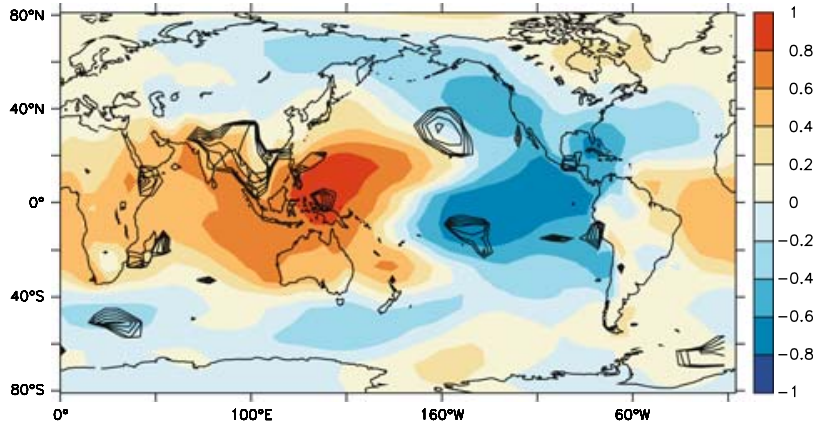

d) ECHAM5/MPI-OM (1860-2000)

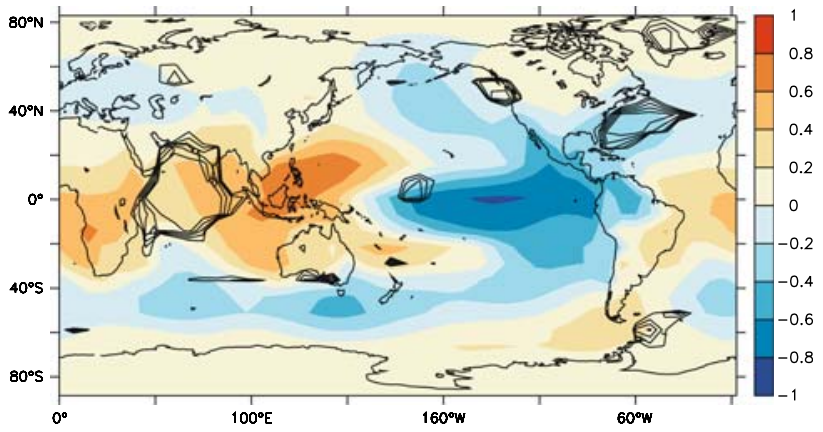

and (b). Superimposed as black contours is the significance of changes in ENSO teleconnection strength (contours between 0.9 and 1 in steps of 0.01) as explained in Sect. 2.2. The fraction of area within the 0.9 contour is $A_{\text {sig }}$ 
a) Hadley (1871-1998)

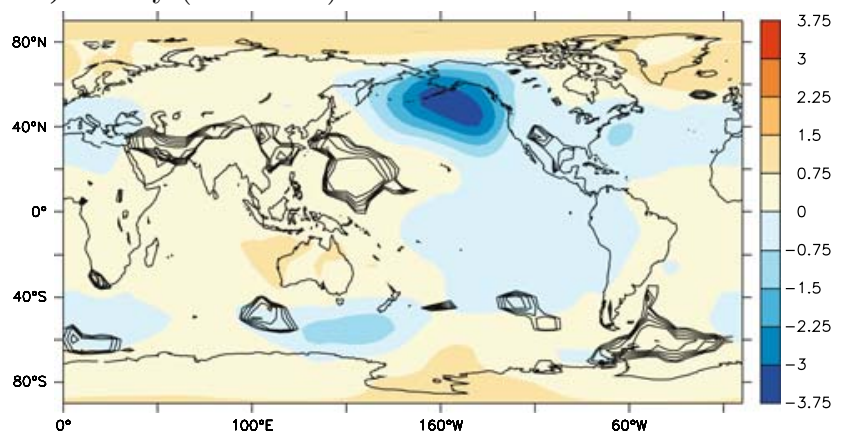

c) Speedy (1881-2002)

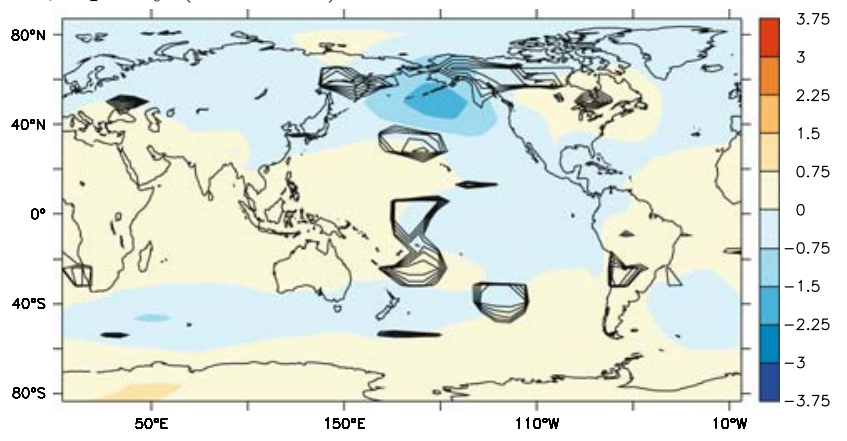

Fig. 2 As Fig. 1, but regression instead of correlations. Units, $\mathrm{hPa} / \mathrm{K}$

tween pressure $p$ and $\mathrm{N}_{34}$, and $\sigma_{p}$ is the observed standard deviation of $p$. By construction $\eta(t)=\left[p(t)-r \mathrm{~N}_{34}(t)\right] /\left(\sigma_{p}\right.$ $\left.\sqrt{1-c^{2}}\right)$ is that part of $p$ that is unrelated to ENSO, i.e., $\operatorname{corr}\left(\mathrm{N}_{34}, \eta\right)=0$. It has zero mean and unit standard deviation.

We now consider sub-periods $P_{W}(t)=[t-W / 2$, $t+W / 2] \subset[0, T]$ of length $W$ of the whole period of length $T$. Following Van Oldenborgh and Burgers (2005) we use a length of $W=25$ years throughout this paper. This is long enough to resolve ENSO and short enough not to be influenced by low-frequency (decadal and longer) variations. For notational convenience we drop the subscript $W$ in what follows. A tilde is used to denote time series restricted to a sub-period, e.g., $\tilde{p}_{t \prime}(t)=\tilde{p}(t)=p(t \mid t \in P(t \prime))$, where the subscript $t^{\prime}$ has been dropped for convenience. Using (Eq. 6) the regression of $\tilde{p}$ on $\tilde{N}_{34}$ then reads

$\tilde{r}(t)=\operatorname{regr}\left(\tilde{N}_{34}, \tilde{p}\right)=r+\sigma_{p} \sqrt{1-c^{2}} \tilde{r}_{\eta}(t)$,

where $\tilde{r}_{\eta}(t)=\operatorname{regr}\left(\tilde{\mathrm{N}}_{34}, \tilde{\eta}\right)$. Apart from the factor $\sigma_{p} \sqrt{1-c^{2}}$ this quantity is the deviation of the regression during $P(t)$ from its long-term mean value $r$. Obviously, $\tilde{r}_{\eta}(t) \rightarrow 0$ in the limit $W \rightarrow T$, but $\tilde{r}_{\eta}(t)$ can be non-zero if the sub-period is so short that it is not influenced by lowfrequency variations in the background state. If $\tilde{r}_{\eta}(t)$ is distributed around zero the long-term mean regression $r$ is a good approximation of $\tilde{r}_{\eta}(t) \forall t$. b) ERA-40 (1957-2002)

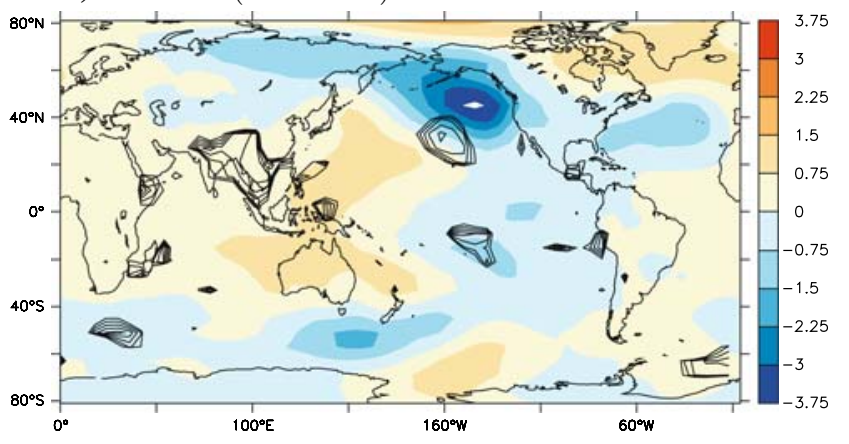

d) ECHAM5/MPI-OM (1860-2000)

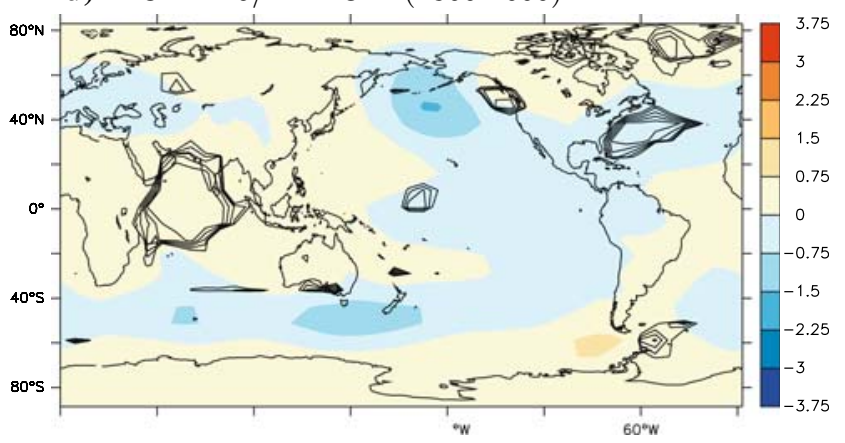

The statement "the strength of the teleconnection does not change significantly with time" means that the variations of $\tilde{r}(t)$ are small in the sense that they are explainable by chance- $-\tilde{r}_{\eta}(t)$ will vary even for a purely stochastic $\eta(t)$. To test this we use a Monte Carlo approach. We replace $\eta(t)$ in (Eq. 1) by a Gaussian process (random number generator from Numerical Recipes; Press et al. 1992) with the same statistical properties (zero mean, unit standard deviation) and simulate the probability density function (PDF) of $\tilde{r}(t)$ by using a large number $(1,000$, say) of stochastic series of $\eta$. If the observed values of $\tilde{r}(t)$ lie within the PDF they are "small", and the strength of the teleconnections does not change. The time series $\tilde{r}(t)$ is stationary (more precisely: nonstationarity cannot be rejected) and observed variations in $\tilde{r}(t)$ can be explained as the result of a stochastic process brought about by the combined action of all non-ENSO processes, represented by $\eta$. Conversely, if the observed values of $\tilde{r}(t)$ lie outside the PDF we can conclude that the teleconnections themselves have changed.

The actual test builds upon these general considerations, but differs in two points. First, we do not use regression but correlation, transformed to Fisher's $z$ values: $z=\frac{1}{2} \log$ $(1+c) /(1-c)$. This quantity is unbounded, estimates are more normally distributed around the true value, and the variance is to a first approximation independent of c. Second, instead of dealing directly with $z$ we use 
$\Delta z=z_{\max }-z_{\min }$, where $z_{\min }$ and $z_{\max }$ are respectively the minimum and maximum of $\tilde{z}(t)$ within all sub-periods of length $W$. Using $\Delta z$ rather than $z$ puts a stronger emphasis on the variations of $\tilde{z}(t)$ (or, equivalently, $\tilde{r}(t)$ ).

\subsection{Determining significance}

$\Delta z$ is determined for each of the stochastic time series of $p$ constructed from (Eq. 1). This yields an estimate of $\mathrm{f}(\Delta z)$, the PDF of $\Delta z$, which is used to test the null-hypothesis $\Delta z_{\text {obs }} \in f(\Delta z)$. An observed value of $\Delta z$ is significantly different from zero at the $x \%$ level if it is outside of the $x \%$ interval of the PDF. This measure of significance is used in this paper. Applying it to each individual grid point gives maps of the significance of change. Regions where the significance exceeds $90 \%$ are highlighted in all plots in this paper.

The fraction of the Earth's surface that is enclosed by the $90 \%$-significance line, $A_{\text {sig }}$, is used to further assess the significance of the detected changes. Naively, one would expect $A_{\text {sig }}=0.1(10 \%)$ from chance alone. However, Livezey and Chen (1983) have shown that care has to be taken when assessing field significance. The problems are multiplicity and dependence. Due to multiplicity the probability of finding $A_{\text {sig }}>10 \%$ by chance is larger than the naively expected $10 \%$ as long as the number of spatial degrees of freedom (s-DoF) is finite. For a gridded field the number of s-DoFs would equal the number of grid points if the grid points were independent. However, neighbouring points of a physical field (e.g., $z_{500}$ ) are not independent, strongly reducing the number of effective s-DoFs.

To estimate the number of s-DoFs of the significance field we follow a procedure very similar to the one usually employed in time series analysis (e.g., Efron and Tibshirani 1998). We first calculate the spatial autocorrelation function of the field as a function of the (binned) great circle distance between pairs, thereby thinning the lat-lon grid near the poles to keep approximately the same grid point density. A decorrelation length, $\alpha_{\mathrm{d}}$, is defined as the distance (in degrees) over which the correlation drops below $1 / e$ (e-folding). Just as one estimates the number of degrees of freedom of a time series as the number of samples divided by the decorrelation length, we estimate the number of spatial DoFs, $N$, as the area of the sphere divided by the area of a circle of radius $\alpha_{\mathrm{d}}$ :

$N=\frac{4 \pi R^{2}}{2 \pi R^{2}\left(1-\cos \alpha_{\mathrm{d}}\right)}=\sin ^{-2} \frac{\alpha_{\mathrm{d}}}{2}$.

Applying this method to the various fields of significance yields values between $\alpha_{d}=9^{\circ}$ and $15^{\circ}$, with the bulk of the values around $12^{\circ}$. There is no clear relation between the $\alpha_{\mathrm{d}}$ values and variable (SLP or $z_{500}$ ) or dataset. The range of $\alpha_{\mathrm{d}}$ values is even found between the members of the model ensembles.

According to (Eq. 3) the given range of $\alpha_{\mathrm{d}}$ corresponds to between 162 and 58 s-DoFs, which, according to Fig. 6 of Livezey and Chen (1983) means that $A_{\text {sig }}$ must exceed $13-16 \%$ to be field significant at the $90 \%$ level. In order to avoid the complication of determining $N$ for each data field separately we take the lowest value, $13 \%$, as our significance limit. This choice means that we might label some changes as significant while in fact they are not. However, our conclusions do not depend on this choice-choosing a higher significant level would only strengthen our point.

\subsection{Observational data}

The only reliable data describing the global atmospheric circulation that are available for a long period of time are those of sea level pressure (SLP). We use the data set HadSLP1, a reconstruction of SLP performed by the Hadley Centre. It is an update of the earlier global mean sea level pressure (GMSLP) data set (Basnett and Parker 1997) and encompasses the period 1871-1998. The NINO3.4 index is derived from HadISST_1_1, a reconstruction of global SST from the Hadley Centre (Rayner et al. 2003).

HadSLP is a reconstruction based on EOFs derived from recent periods with high data coverage. The reconstruction method biases it towards preserving present-day covariances, suppressing possible changes in the strength of the teleconnections. The results obtained from this dataset therefore have to be taken with care.

For a shorter period of time (Sept. 1957-Aug. 2002) also data from the ERA-40 reanalysis (Uppala et al. 2005) are used. A reanalysis is a model run constrained by all available observations. For pressure data the constraint is very large, and the ERA-40 data can be regarded as pseudo observations. They have the advantage of also containing upper air data. In this study the height of the $500 \mathrm{hPa}$ level $\left(z_{500}\right)$ is used.

\subsection{Model data}

Data from three different modelling efforts are used in this study. They encompass a relatively simple Atmospheric General Circulation Model (AGCM) driven by reconstructed SST, a large ensemble obtained using a coarseresolution climate model, and a small ensemble from a high-resolution climate model. Only a short description is given in the following, and the reader is refereed to the original publications for more information. The NINO3.4 index is computed from either the prescribed SST (atmosphere-only runs) or the modelled SST (coupled runs). Depending on data availability the large-scale atmospheric circulation is represented by SLP or by $z_{500}$. 


\subsubsection{Speedy}

The fast AGCM Speedy (Molteni 2003) has been forced by SST anomalies derived from the extended reconstruction of global sea surface temperatures (ERSST) dataset of Smith and Reynolds (2003). This dataset spans the time from 1854 onwards and is regularly updated. As data quality is poor before 1880 we only use the period 1880 to 2002 . Being a reconstruction ERSST suffers from the same bias towards present-day covariances as does HadSLP (see Sect. 2.3). However, SST is only used as the lower boundary condition, and the AGCM is free to react to the varying SST. There is no constraint on the covariances between the forcing SST and the resulting circulation.

The Speedy version used here has seven vertical levels and a horizontal resolution of T30. Speedy employs a simplified physics parameterization. Compared to the original version of Molteni (2003) some changes have been implemented (Hazeleger et al. 2003), the most important one being a modification of the cloud parameterization. To increase the signal to noise ratio ensembles of runs have been performed. From the three ensembles described by Sterl and Hazeleger (2005) we use the one in which SST anomalies are applied globally. To avoid spin-up effects the first year (1880) is discarded.

\subsubsection{CCSM 1.4}

In the Dutch Challenge Project (Selten et al. 2004) the NCAR Community Climate System Model, version 1.4 (CCSM 1.4) has been used to perform a 62 member ensemble of past and future climate. The atmosphere component of this coupled climate model has a horizontal resolution of T31 and 18 vertical layers. The ocean component has 25 vertical layers. Its zonal resolution is comparable to that of the atmosphere, while its meridional resolution is about twice as high and even higher near the equator. The model is completed by sea-ice and land components. No flux correction is applied. The coupled model is forced by varying the concentration of greenhouse gases (GHG), the solar irradiance, and the concentration of stratospheric (volcanic origin) and anthropogenic (sulfur) aerosols. For the period 1940-2000 these forcings are taken from historical estimates. For the future period 2001-2080 solar irradiance and aerosol concentration are held constant at their year 2000 values, but the GHG concentration is increased following a buisiness-as-usual scenario that is close to SRES scenario A1b. By analyzing not only the whole period, but also the sub-periods 1860-2000 and 2001-2080, we separate the effects of past and future changes.

Zelle et al. (2005) have investigated ENSO variability in the Challenge runs. They find a SST variability that is only slightly less than the observed one, but unskewed. The atmospheric response to SST anomalies in the tropics, however, is too weak and independent of the background SST. Consequently, there is no change of ENSO behaviour in a warming climate.

\subsubsection{ECHAM5/MPI-OM}

In preparation of the fourth assessment report (AR4) of the Intergovernmental Panel on Climate Change (IPCC) a number of modeling centers have performed runs with their coupled climate models. A comparison in terms of atmospheric circulation revealed the coupled ECHAM5/MPIOM (Jungclaus et al. 2005) model of the Max-PlanckInstitute of Meteorology in Hamburg as one of the better of these models in terms of the physics of the ENSO cycle (Van Oldenborgh et al. 2005) and the global and regional circulation patterns (Van Ulden and Van Oldenborgh 2005). Two three-member ensembles are available. The runs start in 1860 and use observed forcing until 2000. After that aerosols and solar irradiance are kept constant, while GHG concentrations keep rising according to SRES scenarios A1b or A2 until 2100. The A1b runs continue until 2200 with GHG concentrations kept constant at their 2100 levels. Besides considering the whole period we also analyze the sub-periods 1860-2000 (historic), 2001-2100 (rising) and 2101-2200 (stabilized) separately. For the historic period the two ensembles are identical.

Teleconnection changes in the A1b ECHAM/MPI-OM runs have been analyzed by Müller and Roeckner (2006). They compare the difference patterns between phases of high and low ENSO indices, respectively, of the $500 \mathrm{hPa}$ height in the Northern Hemisphere for the three eras historic, rising, and stabilized as defined above. They find an intensification of both the Pacific-North America pattern and the North Atlantic Oscillation and a stronger correlation of their indices with ENSO for the future periods, especially for the twenty-second century (stabilized).

\subsection{Data preparation}

For all datasets anomalies are formed by subtracting the mean annual cycle. This is done in the usual way by subtracting from each individual month the long-term mean of the corresponding calendar month. Additionally, a linear trend could be removed. However, most datasets do not contain one dominant linear trend. Past periods are characterized by low frequency variations rather than trends, and the simulations using CCSM 1.4 or ECHAM5/MPIOM exhibit clear trends only during the twenty-first century when GHG concentrations increase. For these runs it is more appropriate to subtract the dominant global warming signal, i.e., the regression of the field in question on the global-mean near-surface temperature. 
However, our method deals with correlations over short (25 years) sub-periods. As long as the length of the sub-periods is too short for the correlation over this period to be dominated by the low-frequency trend, areas for which significant changes in ENSO teleconnection strength are found are independent of whether or not a low-frequency component (linear trend, global warming signal) has been subtracted from the data. For windowlengths $W>$ rapprox50years results obtained from data with or without the low-frequency component subtracted begin to differ. The results presented in this paper are for anomalies and a fixed window-length of 25 years.

Throughout the paper we show results for individual calendar months (January, February, etc.), obtained by using only January (say) values for both $\mathrm{N}_{34}$ and SLP or $z_{500}$, respectively. Doing so we get rid of the annual cycle in teleconnection strength which otherwise would complicate the analysis. Although lag-correlations are important in some teleconnections, we do not consider them in this global analysis. As the atmosphere adjusts to perturbations within 2 weeks or so, most teleconnections show up quickly and, using monthly means, are captured at zero lag.

a) ERA-40 (1958-2002)

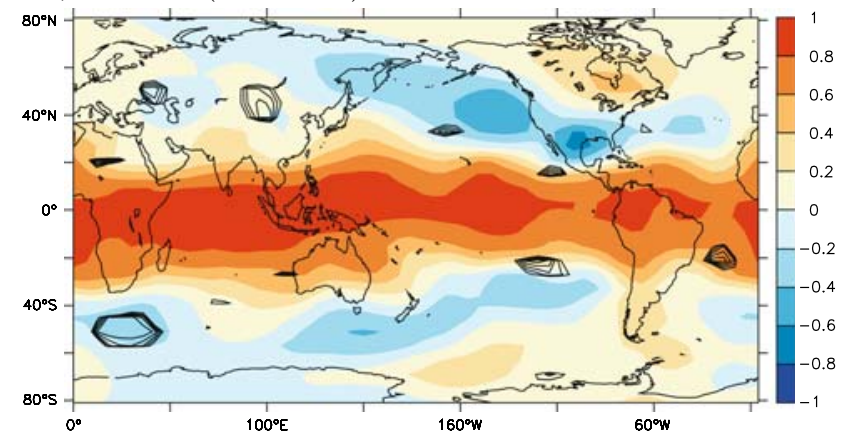

c) ECHAM5/MPI-OM (1860-2000)

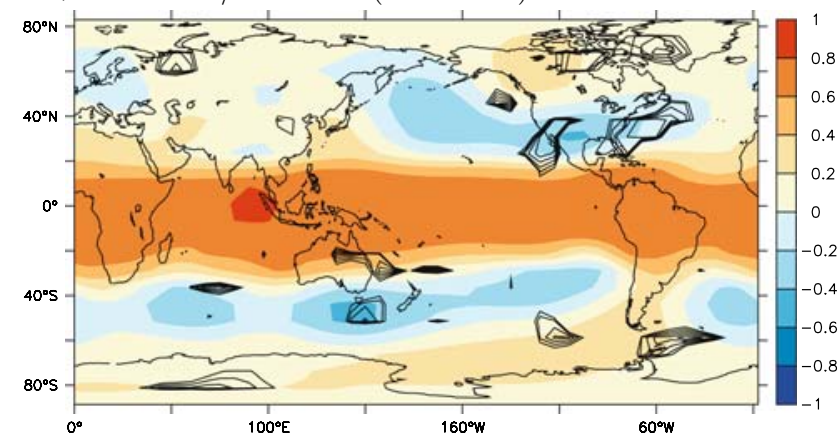

Fig. 3 Correlation between the NINO3.4 index and $z_{500}$ in January for a observations (ERA-40), b Speedy, c ECHAM5/MPI-OM, and d CCSM 1.4. Model results are for the whole ensembles, and only the

\section{Results}

\subsection{Teleconnections in model and data}

To assess the ability of the different models to reproduce the observed teleconnections between ENSO and the atmospheric circulation, Figs. 1 and 3 compare observed and modelled correlations between the NINO3.4 index and SLP and $z_{500}$, respectively. Additionally, Fig. 2 displays the regression of SLP on $\mathrm{N}_{34}$. For the model ensembles the correlations are calculated from time series obtained by concatenating all ensemble members. Averaging would destroy the ENSO signal as it occurs at different times in different members. Since all members are obtained from the same model with the same forcing they have the same means and variances so that concatenation is no problem.

In general the correlation patterns from observations and models show a large degree of similarity. For SLP the familiar east-west gradient over the Pacific Ocean (the Southern Oscillation) emerges. For $z_{500}$ correlations are high throughout the tropics, and a wave train emerges from the western tropical Pacific (about $150^{\circ} \mathrm{W}, 30^{\circ} \mathrm{S} / \mathrm{N}$ ) and propagates into the extra-tropics of both hemispheres b) Speedy $(1881-2002)$

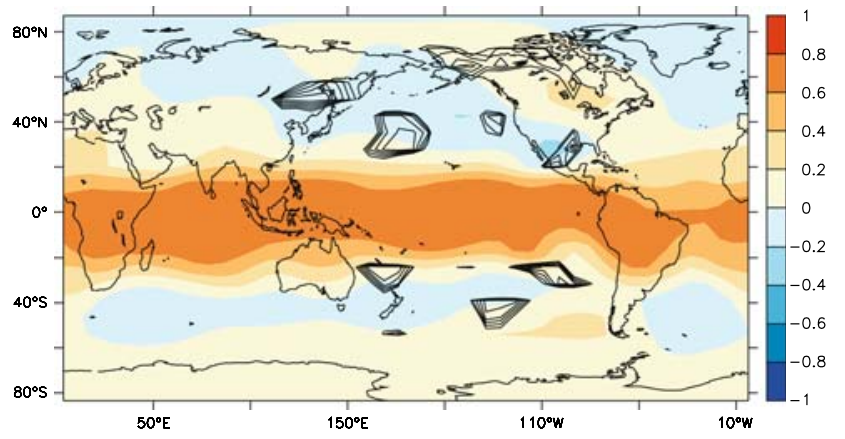

d) CCSM $1.4(1940-2000)$

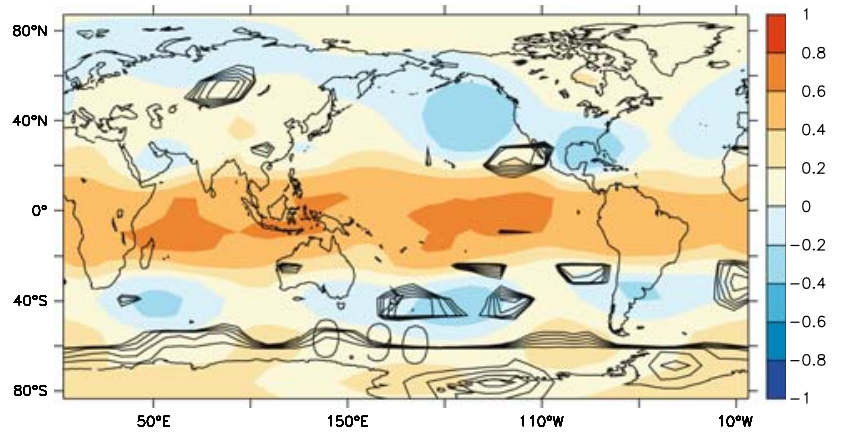

historical period (before 2000) is used for (c) and (d) for better comparison with (a) and (b). Black lines as in Fig. 1 

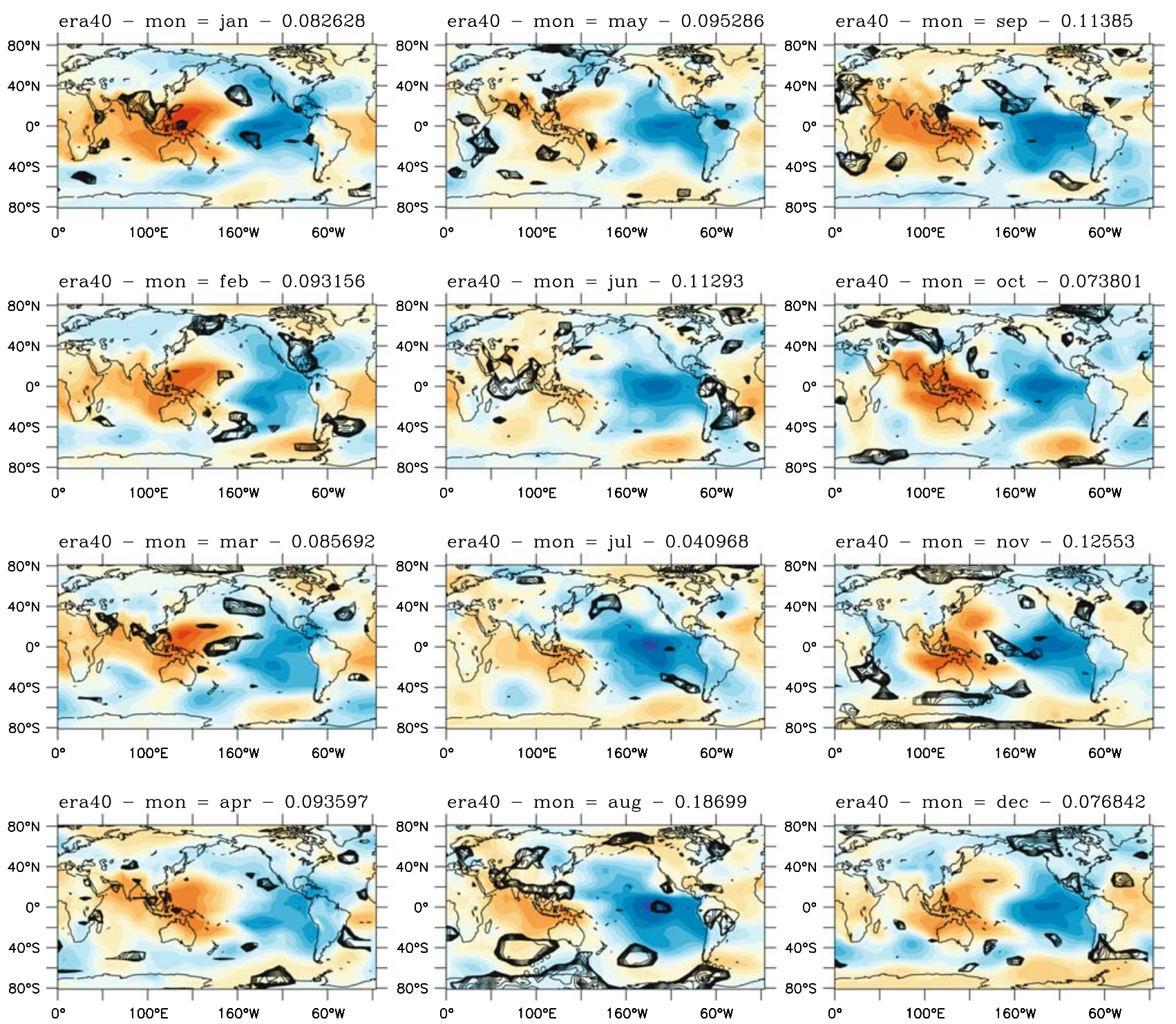

Fig. 4 Correlation (filled colors; key as in Fig. 1) between the NINO3.4 index and SLP in ERA-40. The superimposed black contours are significance values as in Fig. 1. The corresponding $A_{\text {sig }}$ values are given in the label above each panel

(trough over the eastern North Pacific, crest over North America, mirrored in the Southern Hemisphere). There are, however, also obvious differences. For instance, the SLP teleconnections in Speedy seem to be too weak outside the tropics and exhibit less zonal variation than those inferred from observations. The $z_{500}$ teleconnections are weaker and more zonal in CCSM 1.4 than in both observations (reanalysis) and Speedy. However, we feel these differences to be small enough to justify the use of the models for the purpose of this study.

\subsection{Do teleconnections change in observations?}

To investigate whether there are statistically significant temporal variations of the ENSO teleconnections in the observations we apply the method described in Sect. 2.1 to the Hadley and to the ERA-40 data. For SLP from ERA-40 the result is shown in Fig. 4, where the significance of changes in the strength of the ENSO teleconnections is superimposed on the correlations for each calendar month separately. Areas of detected significant changes occur mainly where correlations are low and/or have strong gradients. Our method is most efficient in detecting changes in regions of low correlation (Van Oldenborgh and Burgers 2005). In regions of strong correlation gradients changes are easily brought about by slight changes in the position of the correlation pattern. Depending on unknown other factors, a region may sometimes be influenced by ENSO and sometimes not. It is therefore reasonable to find significant changes in the strength of ENSO teleconnections just here. 
Table $1 A_{\text {sig }}$ for Hadley and ERA-40

Values exceeding the statistical significance level of $13 \%$ (Sect. 2.2) are in boldface

\begin{tabular}{lcrlrlrlrrrrr}
\hline Month & 1 & \multicolumn{1}{c}{2} & \multicolumn{1}{l}{3} & \multicolumn{1}{l}{5} & \multicolumn{1}{l}{6} & \multicolumn{1}{c}{7} & \multicolumn{1}{c}{8} & 9 & 10 & 11 & 12 \\
\hline Hadley (SLP) & 7.7 & 12.1 & 8.6 & 6.1 & 9.4 & 4.8 & 9.1 & 7.5 & 8.6 & 12.6 & 11.5 & 5.5 \\
ERA-40 (SLP) & 8.3 & 9.3 & 8.6 & 9.4 & 9.5 & 11.3 & 4.1 & $\mathbf{1 8 . 7}$ & 11.4 & 7.4 & 12.6 & 7.7 \\
ERA-40 ( $\left.z_{500}\right)$ & 4.4 & 11.8 & 5.3 & 10.8 & 8.2 & 8.3 & 5.6 & $\mathbf{1 7 . 7}$ & 9.1 & $\mathbf{1 4 . 7}$ & $\mathbf{2 1 . 8}$ & 9.8 \\
\hline
\end{tabular}

For detected changes to represent a physical signal one expects them to occur in roughly the same areas in subsequent months. However, Fig. 4 shows that detected areas of significant changes are scattered around the globe with no apparent month-to-month consistency. Their distribution seems to be governed by chance rather than physics.

The $A_{\text {sig }}$ values are displayed on top of each panel of Fig. 4 and reappear in Table 1 together with those for $z_{500}$ and for SLP from the Hadley data. For most months they are clearly explained by chance, not exceeding $13 \%$. Exceptions in the case of ERA-40 are August $\left(z_{500}\right.$ and SLP), November and December $\left(z_{500}\right)$. From a purely statistical point of view changes in the strength of ENSO teleconnections must therefore be considered significant in these 3 months. On the other hand one expects 3.6 tests out of 36 to yield a significant answer at the $90 \%$ level just by chance. Furthermore, in both cases the patterns of detected changes in adjacent months are distinctively dissimilar, strongly questioning the physical significance of the detected changes.

Despite the fact that the Hadley SLP data and ERA-40 are not completely independent as SLP observations have been assimilated into ERA-40, the areas with detected significant changes in both datasets show no signs of correspondence (Fig. 1). This is also true if we confine the analysis of HadSLP to the period that overlaps with ERA40. For this period also the problem that the reconstruction tends to preserve present-day covariances (see Sect. 2.3) is less severe as it contains much more data than earlier periods. Together this provides evidence that detected changes of teleconnection strength are a result of chance rather than reflecting a real change.

Van Oldenborgh and Burgers (2005) find that observed temporal variations in the ENSO to precipitation teleconnections cannot be distinguished from noise. We find the same for the pressure (SLP and $z_{500}$ ) teleconnections. Pressure and precipitation are related, but pressure fields are smoother than those of precipitation, and changes should show up more easily. Despite this no statistically significant changes are found. Together we have to conclude that the physics behind the ENSO teleconnections has not changed in the past to the extend that the changes are detectable in monthly correlations over the last 100 years or so.
3.3 Do teleconnections change in the models?

\subsubsection{Speedy}

The Speedy ensemble consists of 20 runs forced by the same SST. Information on the robustness of detected changes in teleconnection strength can thus be gained from a comparison of teleconnection patterns and their changes in the different runs. More formally the same information can be obtained by considering the whole ensemble together. This is achieved by concatenating (the sub-periods from) all members.

For the month of January Fig. 5 displays the same information as Fig. 4, but for all Speedy members as well as the whole ensemble (all members concatenated). Outside the tropical belt the strength of the teleconnections is generally low and varies a lot between ensemble members. The size and position of regions with statistically significant changes in teleconnection strength also vary much between members. As for ERA-40, areas of significant change tend to occur in regions of low correlations and/or large correlation gradients. Repeating the exercise for the other months gives the same picture of areas with significant variations in the strength of the teleconnections differing a lot between members. Like for the observations there is little consistency between subsequent months. In the case of January (Fig. 5) $A_{\text {sig }}$ varies between $6.4 \%$ (member ER3) and 20.9\% (member E53) and about half of the members have $A_{\text {sig }}$ values that exceed $13 \%$ and must therefore be regarded as statistically significant. However, the large variations between members and the lack of month-to-month consistency casts doubt on this interpretation.

These doubts are confirmed by jointly analyzing all members. The result (lower right panel of Fig. 5) shows an area of significant changes in the Pacific on the border between positive and negative correlations, where changes can be easily brought about by slight changes in the position of the transition zone. Thus, a significant change in the strength of the teleconnection cannot be excluded, and a physical explanation is easy: the westward extent of the warm SST during an ENSO event varies a lot, and this is reflected in the position of the atmospheric response. However, despite the forcing being the same in all runs 


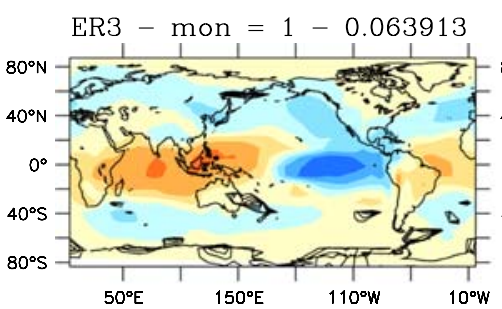

E60 - mon $=1-0.077546$

E54 - mon $=1-0.088658$

ER4 - mon $=1-0.17573$
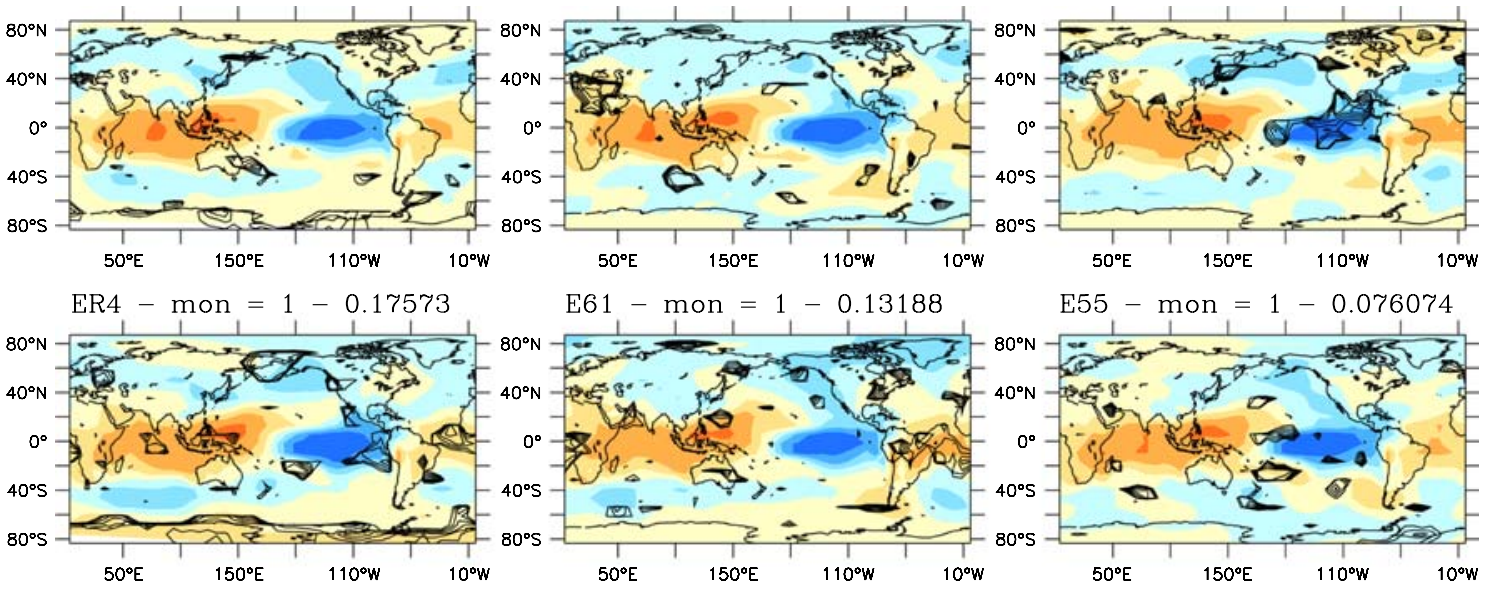

$\mathrm{E} 61-\mathrm{mon}=1-0.13188$

$\mathrm{E} 55-\mathrm{mon}=1-0.076074$

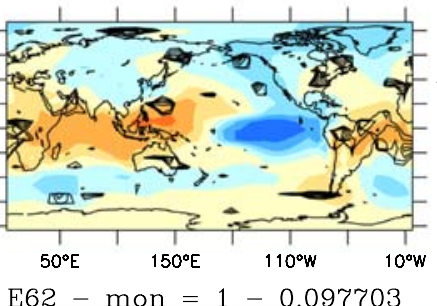

ER5 - mon $=1-0.18792$

$\mathrm{E} 62-\mathrm{mon}=1-0.097703$
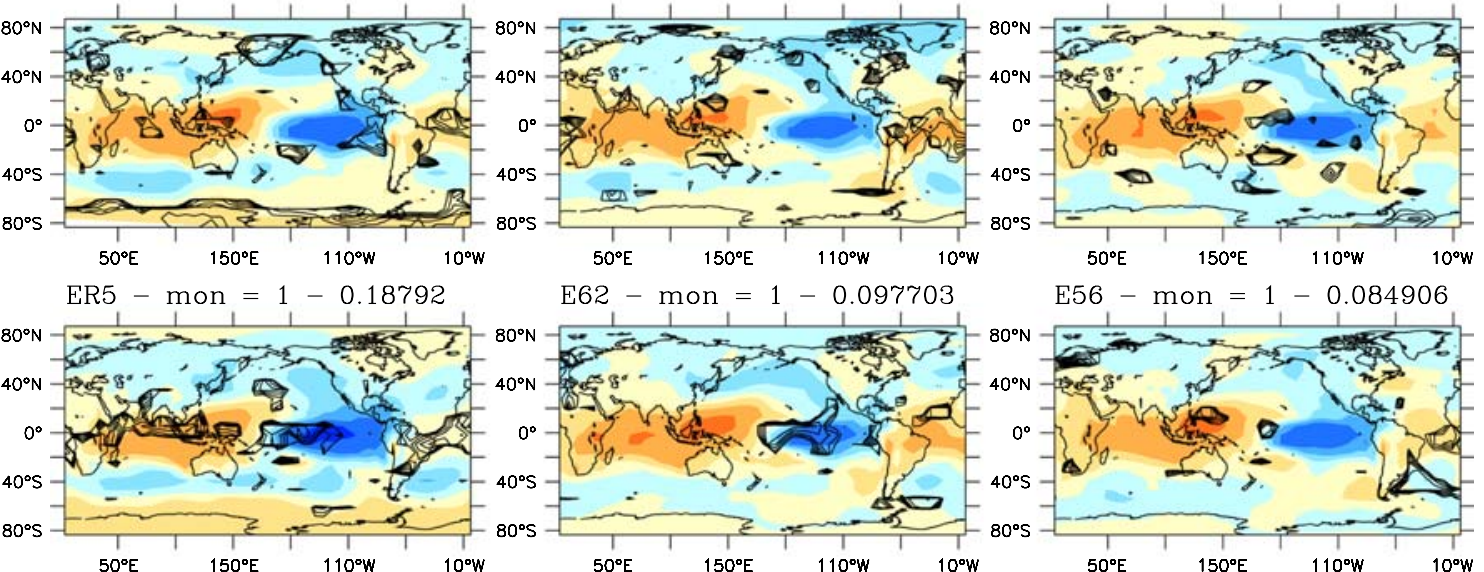

E56 - mon $=1-0.084906$

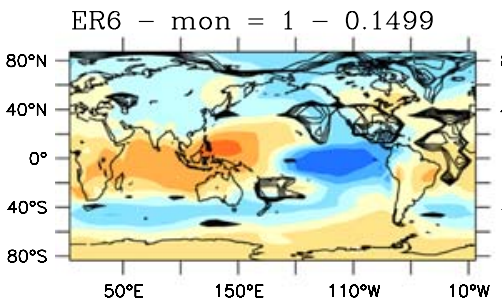

$\mathrm{E} 50-\operatorname{mon}=1-0.076749$

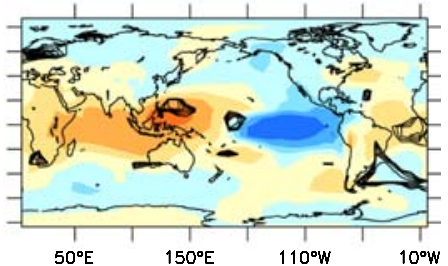

$\mathrm{E} 57-\mathrm{mon}=1-0.14755$

ER7 - mon = $1-0.11299$
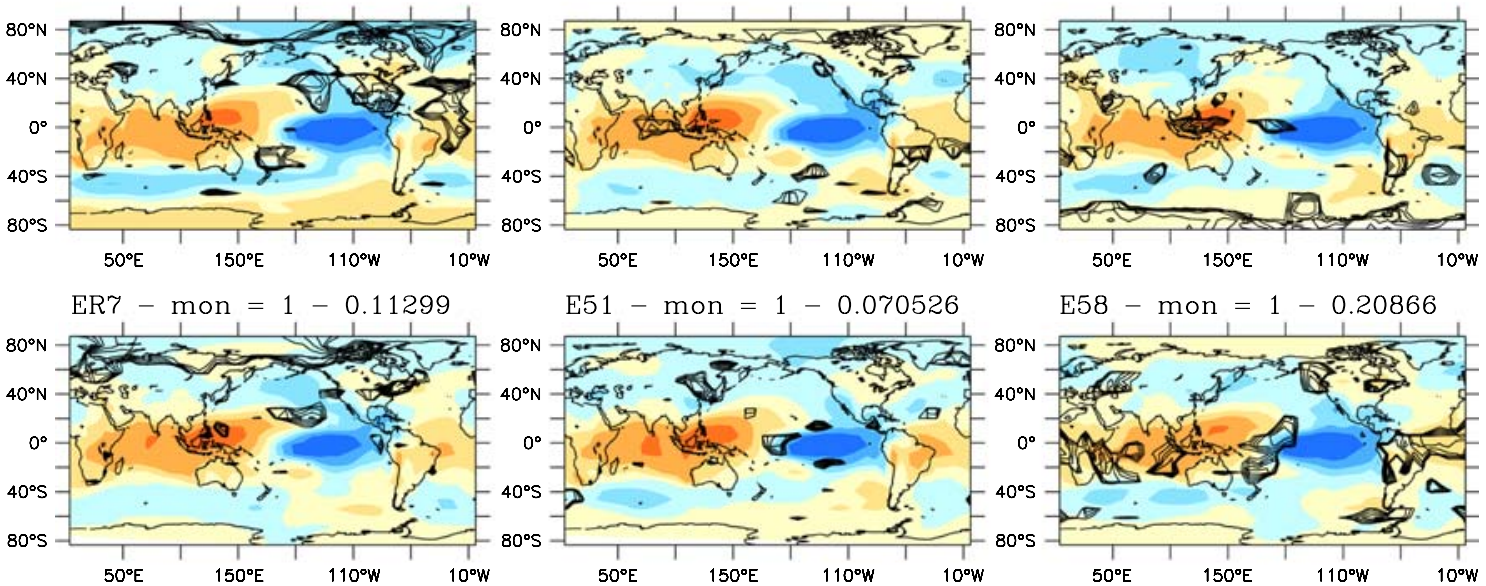

$\mathrm{E} 51-\mathrm{mon}=1-0.070526$

E58 - mon $=1-0.20866$
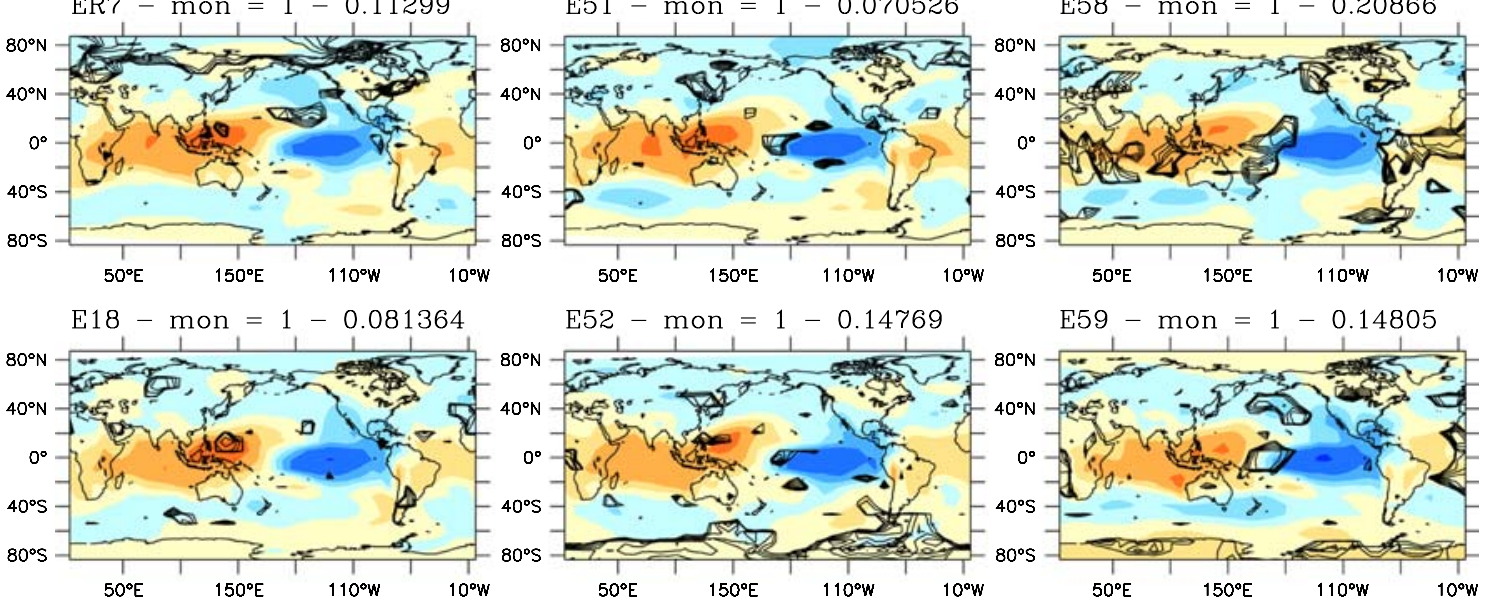

$\mathrm{E} 52-\mathrm{mon}=1-0.14769$

E59 - mon $=1-0.14805$

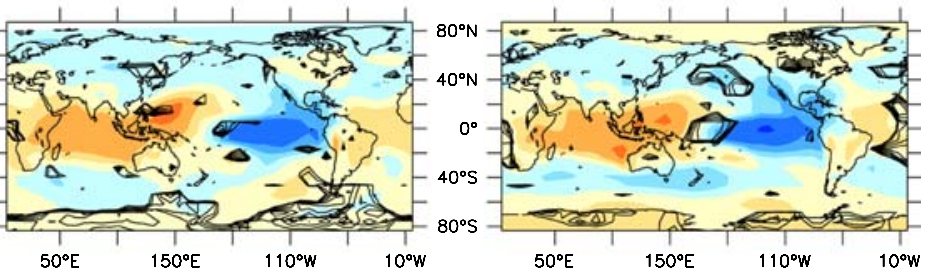

$\mathrm{E} 19-\mathrm{mon}=1-0.082237$

$\mathrm{E} 53-\mathrm{mon}=1-0.20866$
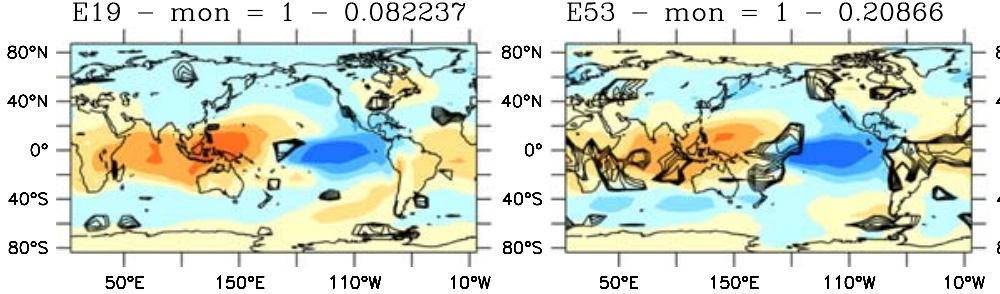

$\mathrm{S} 1-\operatorname{mon}=1-0.10098$

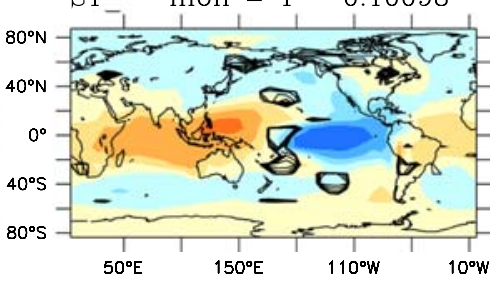

Fig. 5 As Fig. 4, but for January of the 20 members of the Speedy ensemble as well as for the whole ensemble (lower right panel). The text on top of each panel denotes the internal run number, the month, and $A_{\text {sig }}$ 
Table $2 A_{\text {sig }}$ for the Speedy-ensemble (all members combined)

\begin{tabular}{lllllllllllll}
\hline Month & 1 & 2 & 3 & 4 & 5 & 6 & 7 & 8 & 9 & 10 & 11 & 12 \\
\hline
\end{tabular}

$\begin{array}{lllllllllllll}\text { SLP } & 10.1 & \mathbf{1 3 . 4} & 4.6 & 5.7 & 5.9 & 9.0 & 6.8 & 3.6 & 5.5 & 11.2 & \mathbf{1 4 . 9} & 9.4\end{array}$

$\begin{array}{lllllllllllll}z_{500} & 7.0 & 7.8 & 5.5 & 2.7 & 4.7 & 9.5 & 4.2 & 3.9 & 3.0 & 6.9 & 7.9 & 9.0\end{array}$

Values exceeding the statistical significance level of $13 \%$ are in boldface

Fig. 5 shows that the signal only appears in some of the individual runs, indicating that it is not very robust.

The $A_{\text {sig }}$ values for the ensemble are summarized in Table 2. Most of them can be explained by chance, not exceeding $13 \%$. Like for individual members there is no month-to-month consistency of the changes, and areas of significant changes tend to occur in areas of low correlations. The latter is especially true for November (not shown) for which Table 2 gives the largest $A_{\text {sig }}$ value of nearly $15 \%$. That area lies predominantly over Antarctica, where correlation and regression are virtually zero. From the low month-to-month consistency, the large scatter between members, and the low $A_{\text {sig }}$ values for the ensemble taken together we conclude that the Speedy ensemble shows no evidence of a robust, deterministic signal of ENSO teleconnection changes.

Repeating the analysis for the $500 \mathrm{hPa}$ height yields the same picture. Areas of significant changes in teleconnec-
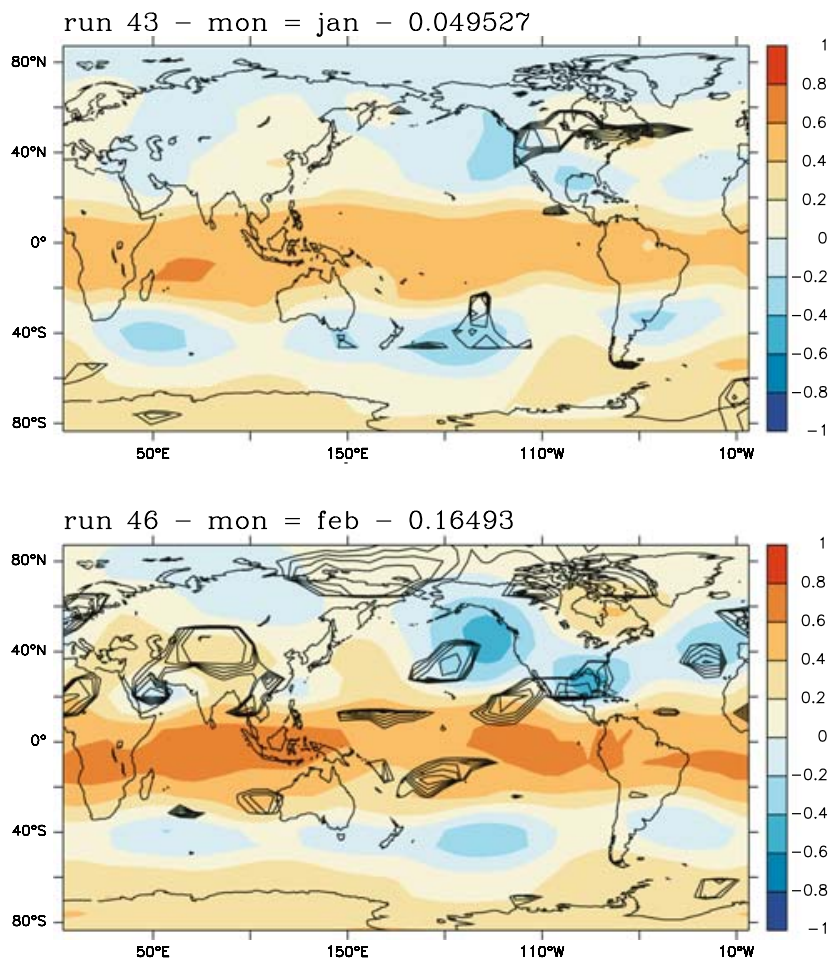

Fig. 6 Some examples of correlations between the NINO3.4 index and $z_{500}$ together with areas of significant changes in these correlations from the CCSM 1.4 ensemble (whole period 1940- tion strength differ widely between ensemble members and months, and $A_{\text {sig }}$ values are even lower than for SLP (see Table 2).

\subsubsection{CCSM 1.4}

The CCSM 1.4 ensemble consists of 62 coupled integrations driven by past and projected greenhouse gas concentrations. Qualitatively, the results from this ensemble are very similar to those from Speedy. Regions of significant teleconnection changes differ widely between individual runs, ranging from 0 to more than $30 \%$ of the Earth's area, and there is no consistency of changes between subsequent months. In runs with a small value of $A_{\text {sig }}$ this area is made up of single spots that seem to be randomly distributed, mainly in regions of low correlation. Runs with a large value of $A_{\text {sig }}$ exhibit large contiguous regions of significant change over the polar regions (where correlations are low) and/or in a narrow strip along the equator. This strip may be explained by the high correlation of $500 \mathrm{hPa}$ height along the equator. Some examples are shown in Fig. 6.

The large differences between individual members result in equivocal results when performing the analysis on (part of) the whole ensemble. Area fractions of significant changes differ a lot depending on using the whole
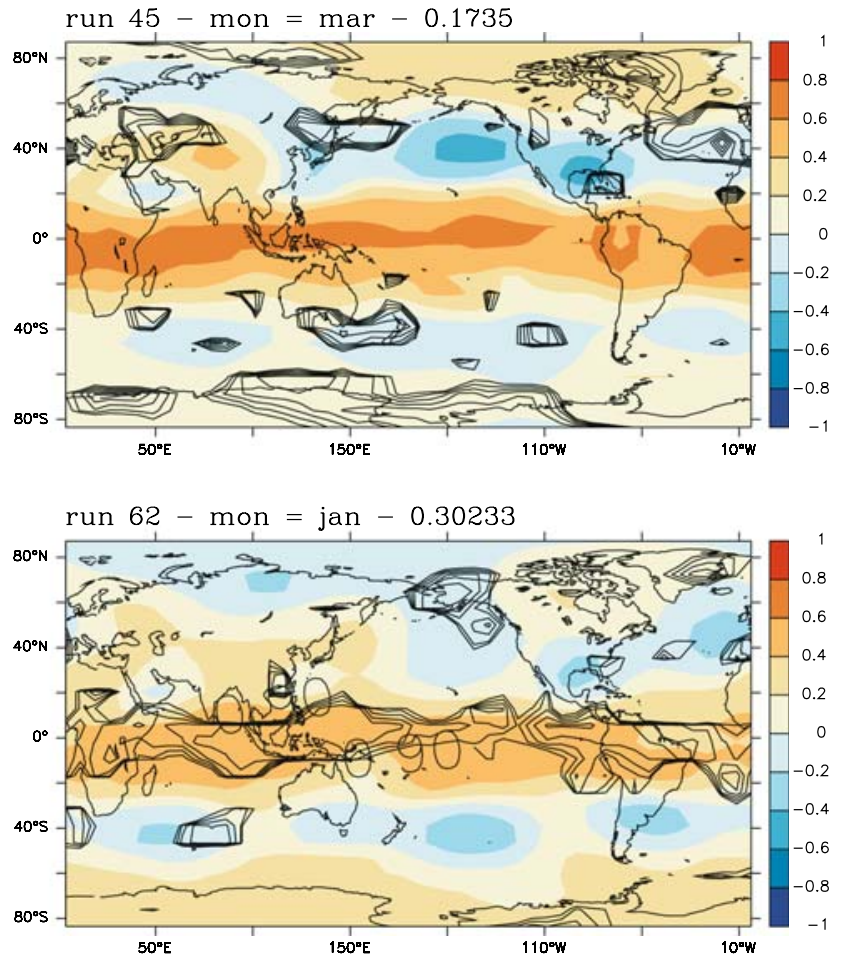

2080). The labels indicate run number, month, and area fraction of significant changes $\left(A_{\text {sig }}\right)$. Shading and contour interval as in Fig. 1 
Table $3 A_{\text {sig }}$ for $z_{500}$ in the CCSM1.4-ensemble

\begin{tabular}{|c|c|c|c|c|c|c|c|c|c|}
\hline & \multicolumn{3}{|l|}{ All members } & \multicolumn{3}{|c|}{ First 31 members } & \multicolumn{3}{|c|}{ Second 31 members } \\
\hline & 1940-2080 & 1940-2000 & $2001-2080$ & 1940-2080 & 1940-2000 & $2001-2080$ & 1940-2080 & 1940-2000 & 2001-2080 \\
\hline Jan & 39.0 & 16.6 & 6.5 & 25.9 & 23.3 & 7.8 & 25.8 & 19.2 & 7.1 \\
\hline Feb & 32.7 & 6.8 & 7.0 & 17.9 & 11.4 & 10.3 & 22.0 & 5.2 & 6.8 \\
\hline Mar & 28.7 & 16.2 & 10.8 & 39.9 & 11.7 & 7.0 & 13.2 & 13.0 & 8.6 \\
\hline Apr & 19.3 & 14.6 & 14.4 & 13.2 & 8.0 & 15.8 & 23.7 & 11.9 & 11.7 \\
\hline May & 10.5 & 7.9 & 10.5 & 11.4 & 28.2 & 5.6 & 11.3 & 6.3 & 12.9 \\
\hline Jun & 21.9 & 31.6 & 9.9 & 17.1 & 31.3 & 8.7 & 14.6 & 20.2 & 13.0 \\
\hline Jul & 19.9 & 24.6 & 9.3 & 33.3 & 26.0 & 13.8 & 7.7 & 4.3 & 12.4 \\
\hline Aug & 23.6 & 14.1 & 6.0 & 35.0 & 11.0 & 14.1 & 12.5 & 11.3 & 12.2 \\
\hline Sep & 22.6 & 16.4 & 25.9 & 22.9 & 12.1 & 34.7 & 6.8 & 15.7 & 4.9 \\
\hline Oct & 7.3 & 10.2 & 10.1 & 8.2 & 6.7 & 11.1 & 3.9 & 7.4 & 6.2 \\
\hline Nov & 11.8 & 8.3 & 8.2 & 10.0 & 13.4 & 7.5 & 12.0 & 11.3 & 14.4 \\
\hline Dec & 12.7 & 27.9 & 5.4 & 16.6 & 30.2 & 3.4 & 5.5 & 5.0 & 10.2 \\
\hline
\end{tabular}

Statistically significant values $(>13 \%)$ are in boldface

ensemble, only the first 31 runs, or only the second 31 runs. The corresponding $A_{\text {sig }}$ values are displayed in Table 3.The number of values exceeding the significance threshold of $13 \%$ is too large to be explained by chance (one-tenth of the entries), suggesting significant changes to be present. However, the large scatter between (sub-)ensembles as well as the large month-to-month variations indicate that this result is not very robust.

The results for the future period (2001-2080) show the smallest variation of $A_{\text {sig }}$ values between months. With two exceptions they are all well below the 13\%-threshold. However, the areas themselves are still erratically distributed over the Globe, and there is no month-to-month consistency (not shown). The low $A_{\text {sig }}$ values might contain a clue as to the underlying mechanism: For the future period 2001-2080 only the concentration of GHGs changes, while the historical period (1940-2000) also experiences changes in aerosols. These changes might induce changes in physics and therefore teleconnections that are missing in the later period. However, more research is needed to confirm this hypothesis, and, if it exists, its impact is small.

The results presented here are in line with those of Zelle et al. (2005), who find that in CCSM 1.4 the atmospheric response to SST variations in the equatorial Pacific is independent of the background SST and thus does not change in a warming climate. Therefore it is not surprising that the strength of ENSO teleconnections does not change.

\subsubsection{ECHAM5/MPI-OM}

Like the CCSM 1.4 ensemble discussed above the threemember ECHAM5/MPI-OM ensemble is forced by past and future GHG concentrations. Results of applying our method to this ensemble are depicted in Fig. 7 and summarized in Table 4.

The $A_{\text {sig }}$ values of SLP over the whole period 1860 2200 clearly exceed the significance level, and a look at the left column in Fig. 7 shows large areas of change that are consistent between months. For example, the region between the positive and negative correlations in the Pacific shows up in most months, especially for boreal winter. This is in line with the finding of Philip and Van Oldenborgh (2006) of more El Niño-like conditions in the future in this model. Two other areas that show up consistently are the Indian Ocean during boreal winter and the Atlantic Ocean during boreal summer.

For the historical period most of the $A_{\text {sig }}$ values are far below the significance level of $13 \%$. This is an independent confirmation of the results obtained from HadSLP and Speedy and does not suffer from the problem of reconstructions being biased as described in Sect. 2.3. If there are no significant changes in the strength of the ENSO teleconnections during the historical period when GHG concentrations were relatively stable (as compared to the rise in the twenty-first century) it is tempting to assume that teleconnection strength would also be quite constant during the twenty-second century and that the detected changes should occur predominantly during the rising period. Indeed, the $A_{\text {sig }}$ values are largest during this period, but the areas do not necessarily coincide between the whole and the rising period (first two columns of Fig. 7). For instance, there are hardly any significant changes in February and December during the twenty-first century, while the changes over the whole period are certainly significant with values of $A_{\text {sig }}$ exceeding the sum of the three sub-periods. Obviously, some changes occur so slowly that they can only be detected over long periods of time. This conclusion 

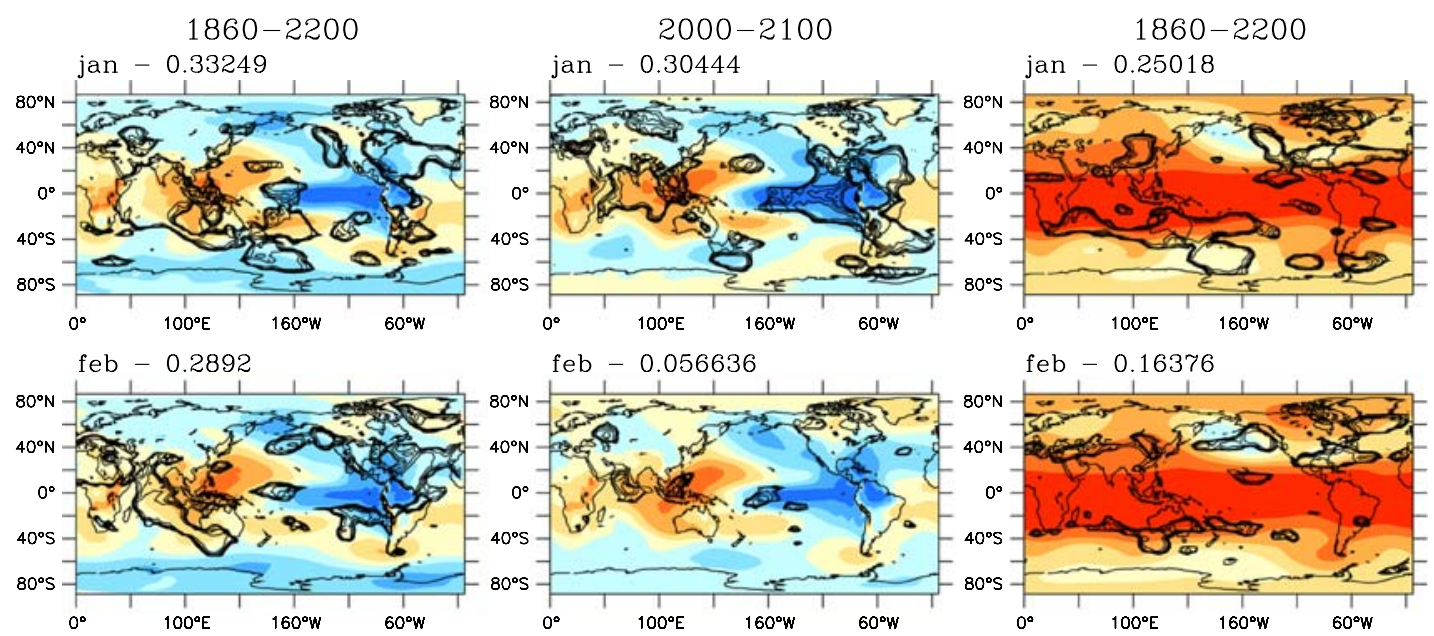

feb -0.056636

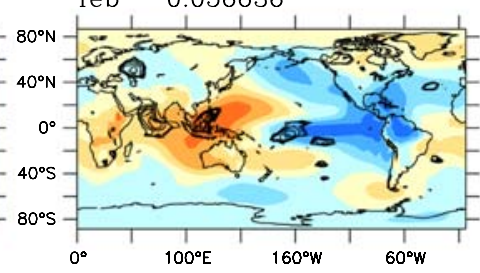

feb -0.16376
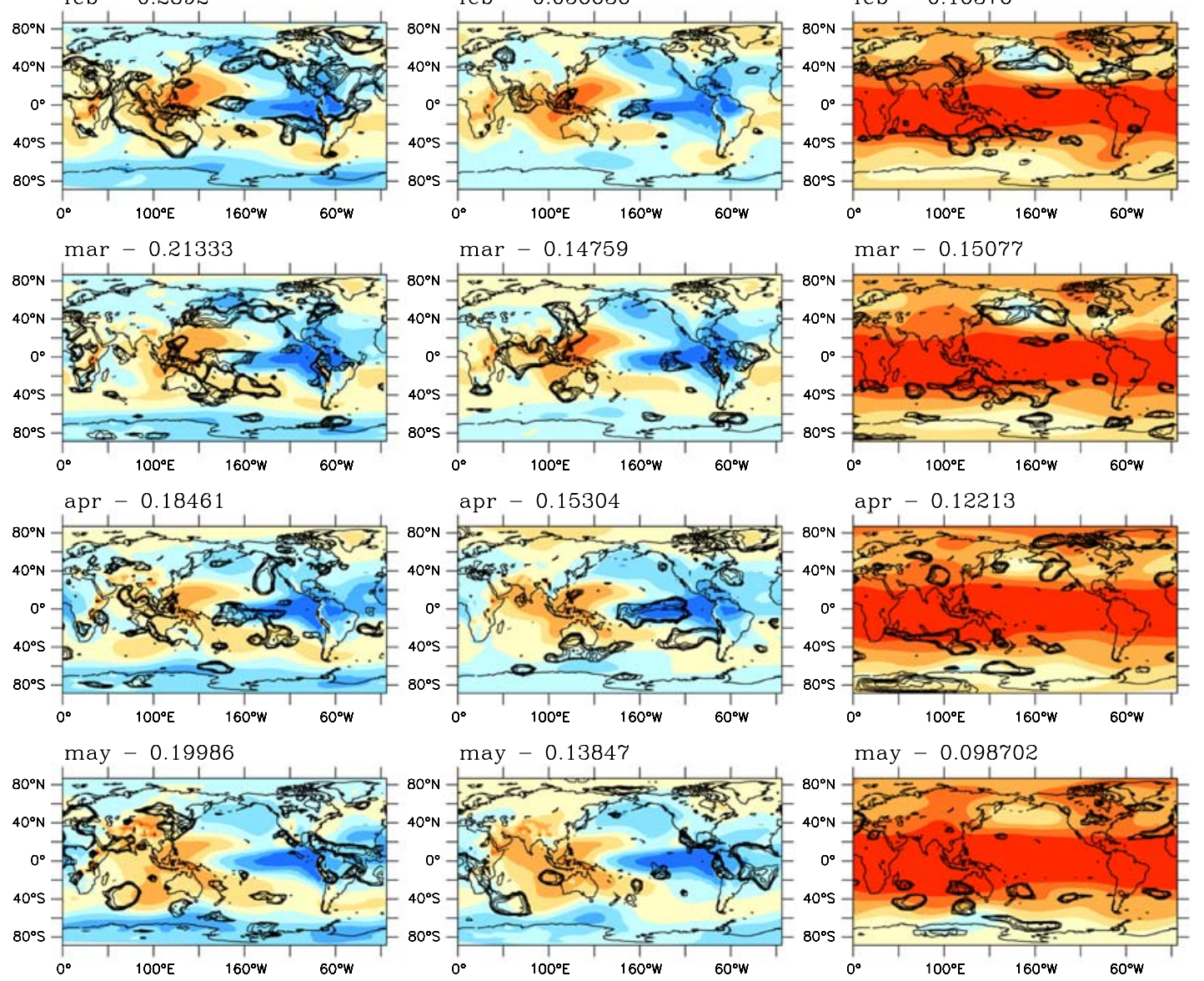

apr -0.12213
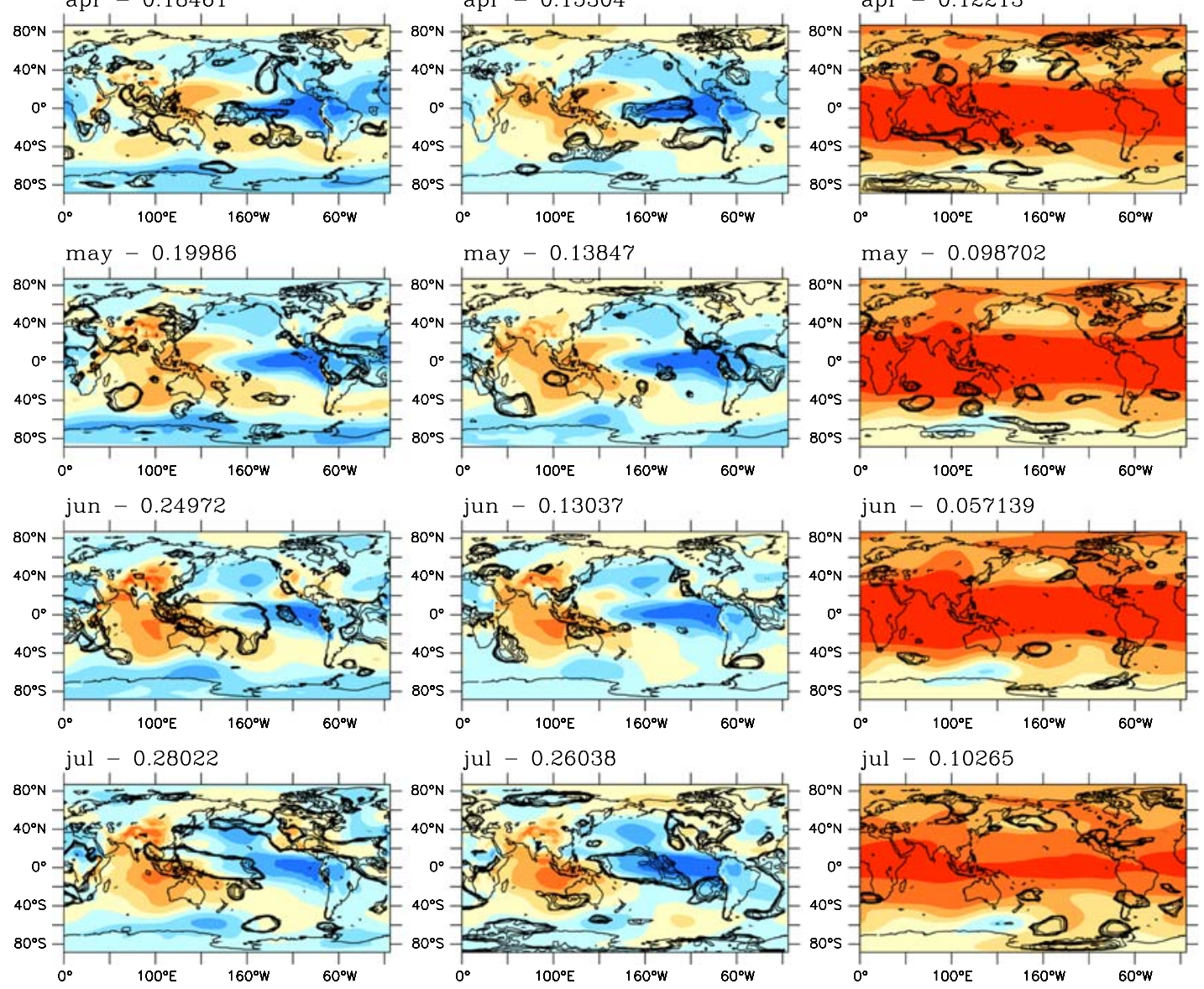

jun -0.057139

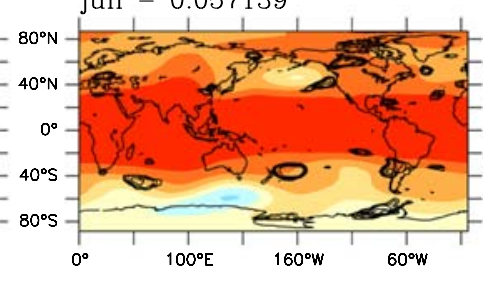

jul -0.10265

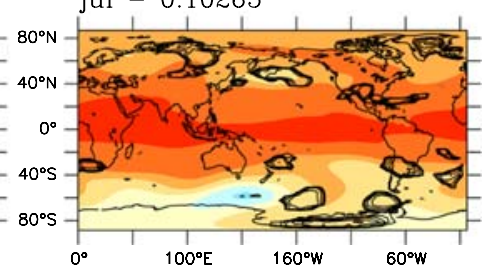

Fig. 7 Correlations and areas of significant changes in the strength of the teleconnections for the ECHAM5/MPI-OM ensemble for the months January to July. Color coding and isolines as in Fig. 1. Left column SLP, whole period; middle column SLP, twenty-first century; right column $z_{500}$, whole period. The number on top of each panel is $A_{\text {sig }}$ 
Table $4 A_{\text {sig }}$ for SLP and $z_{500}$ from the ECHAM5/MPI-OM ensembles for different periods

\begin{tabular}{|c|c|c|c|c|c|c|c|c|}
\hline & \multicolumn{4}{|l|}{ SLP } & \multicolumn{4}{|l|}{$z_{500}$} \\
\hline & $1860-2200$ & $1860-2000$ & $2000-2100$ & $2100-2200$ & $1860-2200$ & $1860-2000$ & $2000-2100$ & $2100-2200$ \\
\hline Jan & $33.3(24.4)$ & 10.5 & $30.4(14.4)$ & 9.1 & $25.0(19.7)$ & 8.3 & $8.7(9.4)$ & 5.5 \\
\hline Feb & $28.9(20.7)$ & 6.3 & $5.7(10.8)$ & 9.6 & $16.4(11.5)$ & 5.1 & $1.9(7.5)$ & 8.6 \\
\hline Mar & $21.3(16.8)$ & 12.5 & $14.8(17.9)$ & 7.7 & $15.1(12.5)$ & 7.4 & $4.3(8.7)$ & 3.9 \\
\hline Apr & $18.5(10.6)$ & 5.6 & $15.3(10.7)$ & 6.3 & $12.2(10.2)$ & 5.6 & $6.8(7.8)$ & 4.3 \\
\hline May & $19.9(21.8)$ & 9.1 & $13.8(17.2)$ & 7.2 & $9.9(11.0)$ & 7.5 & $5.2(8.3)$ & 6.1 \\
\hline Jun & $25.0(19.3)$ & 3.0 & $13.0(19.7)$ & 10.7 & $5.7(6.8)$ & 2.2 & $2.6(9.3)$ & 5.6 \\
\hline Jul & $28.0(20.5)$ & 9.2 & $26.0(10.6)$ & 7.5 & $10.3(5.9)$ & 2.9 & $8.6(8.3)$ & 5.2 \\
\hline Aug & $34.7(15.1)$ & 11.0 & $20.3(15.9)$ & 7.7 & $17.0(7.0)$ & 6.1 & $8.1(3.8)$ & 4.7 \\
\hline Sep & $24.9(16.7)$ & 9.3 & $10.3(9.9)$ & 2.3 & $13.5(10.3)$ & 5.6 & $3.0(7.0)$ & 4.0 \\
\hline Oct & $29.6(14.3)$ & 14.5 & 12.9 (15.9) & 10.2 & $13.0(6.3)$ & 6.2 & $5.9(4.9)$ & 7.1 \\
\hline Nov & $24.8(21.2)$ & 9.6 & 8.4 (13.9) & 6.3 & $10.4(8.9)$ & 6.4 & $3.9(6.6)$ & 5.3 \\
\hline Dec & $41.0(32.2)$ & 10.9 & $5.6(\mathbf{2 2 . 3})$ & 11.7 & $28.2(17.2)$ & 6.0 & $2.5(9.0)$ & 12.2 \\
\hline
\end{tabular}

Entries in parentheses are for the A2 scenario, while the others are for A1b. The former are not available for the period 2100-2200, and for 18602000 the two are identical. For A2, the values in the first column refer to the period 1860-2100 only. Values exceeding the statistical significance level of $13 \%$ are in boldface

is backed by the results from the A2-scenario. GHG concentrations rise faster in this scenario with higher $A_{\text {sig }}$ values during the rising period, yet the $A_{\text {sig }}$ values for the whole period are lower, presumably because A2 has a shorter "whole period" (1860-2100 instead of 18692200).

The $A_{\text {sig }}$ values for the $500 \mathrm{hPa}$ height are (much) lower than those for SLP, exceeding the significance level only for some months and only for the whole period. However, areas with significant changes tend to coincide in the SLP and $z_{500}$ plots (left and right columns in Fig. 7), at least outside the tropical belt (roughly between $20^{\circ} \mathrm{N}$ and $20^{\circ} \mathrm{S}$ ). In the extra-tropics SLP and $z_{500}$ are closely coupled, and if one of them is affected by a changing coupling to ENSO the other must be affected, too. This coincidence is not visible for shorter periods (not shown), indicating that the detection of changes in the strength of the teleconnections is governed by chance rather than by physics. This again adds to the evidence that changes can only be detected reliably over long periods of time.

In their evaluation of changes in the strength of teleconnections Müller and Roeckner (2006) look at correlations between $\mathrm{N}_{34}$ and $z_{500}$ calculated separately over the three periods historic, rising, and stabilized. They find large differences between correlations during the first and the last period in a zonal band stretching along $40^{\circ} \mathrm{N}$ from the North Pacific via North America into the North Atlantic. In the same areas our method indicates significant changes over the whole period (Jan and Feb panels of the right column of Fig. 7).

Taken together the results from the ECHAM5/MPI-OM ensemble indicate that the strength of ENSO teleconnec- tions might change in a future (warming) climate. Areas with likely changes include the central equatorial Pacific Ocean, the Indian Ocean, and parts of the North Atlantic Ocean. However, the areas in which significant changes occur differ between different ensemble members (see Fig. 8). Together with the fact that changes are only detectable reliably over long periods of time (more than a century) this leads to the conclusion that the signal is weak compared to natural variability.

In the ECHAM5/MPI-OM ensemble the $A_{\text {sig }}$ values are larger for the period of rising GHG concentrations than they are for the historical period, while the opposite is true in the CCSM 1.4 ensemble. A possible reason for this discrepancy is the fact that the increase of the average NINO3.4 SST in the latter is much lower than in the former. For CCSM 1.4 the increase is about $1.2 \mathrm{~K}$ until 2080, while for ECHAM5/MPI-OM it is more than $4 \mathrm{~K}$ until 2100. This is another indication that the signal is weak compared to natural variability. It only shows up when the forcing is large.

\section{Summary and conclusion}

ENSO systematically influences the atmospheric circulation in large parts of the globe. These teleconnections are often used to calibrate climate proxy data or to estimate the impact of ENSO events. It is therefore important to know whether they are stationary, meaning that observed variations in teleconnection strength can be ascribed to stochastic fluctuations. The strength of a teleconnection is measured by the linear regression coefficient between the 


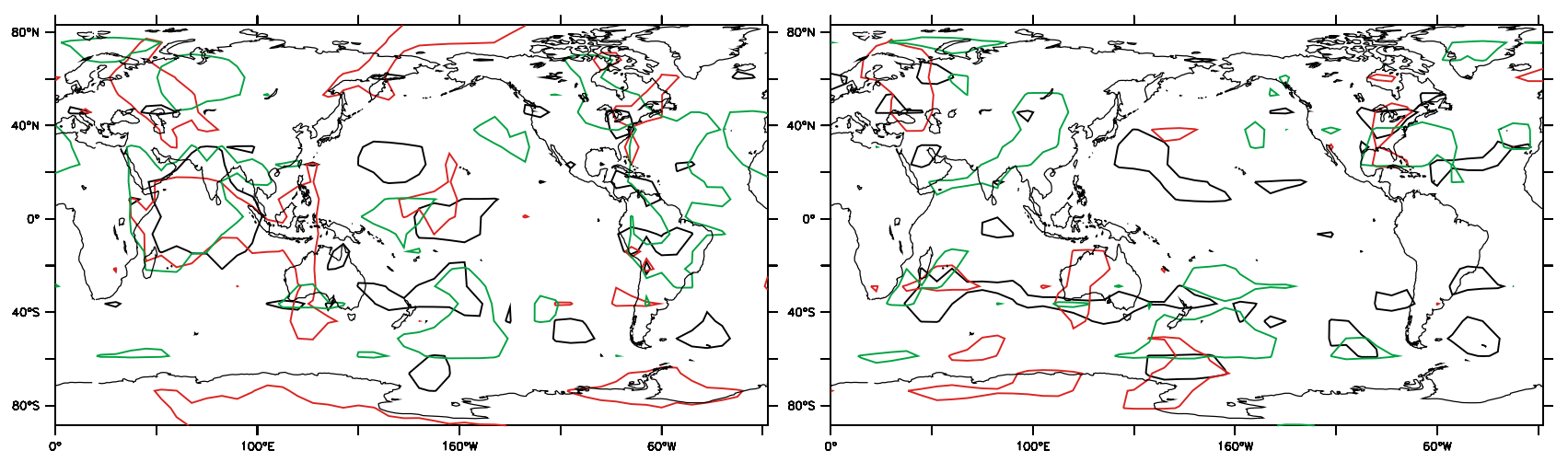

Fig. $890 \%$ significance of detected change in ENSO teleconnection strength for the three ECHAM5/MPI-OM members for SLP (left) and $z_{500}$ (right) for January. Different colors mark the different members

relevant atmospheric quantity and the NINO3.4 index, and a stationary regression time series indicates constant teleconnections strength. The stationarity of the teleconnection strength is assessed by comparing the range of correlation coefficients obtained from data with that to be expected from chance. The former range is obtained by calculating correlation coefficients from the data within sliding 25-year windows, while the latter is obtained using Monte Carlo simulations. Data are obtained from observations, the ERA-40 reanalysis, simulations with a simple atmosphere model (Speedy) driven by observed SST, and two coupled ocean/atmosphere models (CCSM 1.4 and ECHAM5/MPI$\mathrm{OM})$. For the models ensembles of runs are performed to reduce sampling uncertainty.

Regions in which significant changes in teleconnection strength are detected tend to occur in regions of low correlations. For the observations (Hadley, ERA-40) they are scattered around the globe with no month-to-month consistency, and their area fraction can be explained by chance. Therefore, the observational data contain no evidence that the physics of the ENSO teleconnections changed over time. This conclusion is backed by the results from the model integrations. Areas in which significant changes are detected during the historical period are also scattered around the globe and lack consistency in time. Furthermore, they differ greatly between individual members of the ensembles as well as between ensembles. Using reconstructed SLP data reaching back to the early eighteenth century, Brönnimann et al. (2007) find a stationary relationship between ENSO and late winter climate in Europe. Their result backs our conclusion that there are no changes in the strength of ENSO teleconnections in the historical period.

The results from the Speedy ensemble are similar to those from the observations. The regions in which significant changes are found are scattered around the globe without consistency from month-to-month or between members, and their size can be explained by chance. The same lack of consistency is found in the CCSM 1.4 ensemble, where the area in which our method detects significant changes ranges between 0 and $30 \%$ of the Earth's surface between members. Detected changes are slightly stronger during the historical period (1940-2000) than they are over the future period (2001-2080).

Opposite to the results from CCSM 1.4, the coupled ECHAM5/MPI-OM model exhibits more changes over the future period (2001-2100) than over the past (1860-2000). In this model regions with detected changes in the ENSOto-SLP teleconnection appear to be more organized (less scattered), and there is some form of consistency between subsequent months. However, these consistent patterns only show up when the whole period (1860-2200) is considered. Furthermore, areas in which changes occur differ between ensemble members. Together, this indicates that the signal is small compared to natural variability, even with a $4 \mathrm{~K}$ warming signal.

Concluding, the linear ENSO teleconnections itself are stable and robust. We have found no evidence that changes in the strength of the teleconnections between ENSO and the atmospheric circulation went beyond chance during the recent past. Established linear regressions between ENSO strength and circulation therefore seem appropriate for use in climate reconstructions of the past centuries. Whether this is also true for the future depends on the magnitude of the global warming signal. A discernible change in the strength of the ENSO teleconnections is likely to occur only for large changes in the NINO3.4 temperature. Likely areas for changes to occur are the central equatorial Pacific, the Indian Ocean, and parts of the North Atlantic.

Acknowledgments The plotting was done with the free Ferret software developed at NOAA/PMEL/TMAP (see http://www.ferret.noaa.gov). The HadSLP1 and adISST_1_1 datasets where obtained from the Hadley Centre through the British Atmospheric Data Centre (BADC), the ERSST dataset from NOAA through the National Climatic Data Centre (NCDC), the ERA-40 data from ECMWF, and the ECHAM5/MPI-OM from the Max-Planck-Institute for Meteo- 
rology through the IPCC Data Archive at Lawrence Livermore National Laboratory. We thank all these institutions for making their datasets available. A. Buishand (KNMI) gave valuable advice on some aspects of the statistical procedure.

\section{Appendix: Correlation and regression}

Let $a(t)$ and $b(t), t \in[0, T]$, be two time series with zero mean (we $\mathrm{w}_{T}$ are only interested in anomalies). Then $m_{a b}=T^{-1} \int_{0} a(t) b(t) \mathrm{d} t$ is the covariance between the two series and $\stackrel{0}{m a a}_{a a}=\sigma_{a}^{2}$ the variance of $a$, where $\sigma_{a}$ is called the standard deviation of $a$. The correlation between $a$ and $b$ is then given by

$\operatorname{corr}(a, b)=\frac{m_{a b}}{\sigma_{a} \sigma_{b}}=\operatorname{corr}(b, a)$,

while the regression of $b$ on $a$ is

$\operatorname{regr}(a, b)=\frac{m_{a b}}{\sigma_{a}^{2}} \neq \operatorname{regr}(b, a)$.

Correlation is symmetric and dimensionless. Its values are restricted to $[-1,1]$. High positive (negative) values of the correlation are reached if both time series are in phase (antiphase), regardless of their amplitude. For instance, if $b=$ $\varepsilon a$, the correlation between $a$ and $b$ is always \pm 1 , even in the limit $\varepsilon \rightarrow 0$. In this case, regression would go to zero, too. Regression has a dimension of $[b] /[a]$ and tells us how much $b$ varies for a given variation of $a$. An important property of regression is that it is linear in the second argument $(b)$,

$\operatorname{regr}(a, \beta b+\gamma c)=\beta \operatorname{regr}(a, b)+\gamma \operatorname{regr}(a, c)$.

\section{References}

Basnett T, Parker D (1997) Development of the global mean sea level pressure data set GMSLP2. Climate Research Technical Note, 79, Hadley Centre, Met Office, FitzRoy Rd, Exeter, Devon, EX1 3PB, UK

Berlage HP (1957) Fluctuations in the general atmospheric circulation of more than 1 year, their nature and prognostic value. Mededlingen en Verhandelingen No.9, Koninklijk Nederlands Meteorologisch Instituut, Staatsdrukkerij, 's-Gravenhage, The Netherlands, $152 \mathrm{pp}$

Brönnimann S, Xoplaki E, Casty C, Pauling A, Luterbacher J (2007) ENSO influence on Europe during the last centuries. Clim Dyn 28:181-197 doi: 10.1007/s00382-006-0175-z

Efron B, Tibshirani RJ (1988) An introduction to the bootstrap. Chapman and Hall, London, $436 \mathrm{pp}$

Fogt RL, Bromwich DH (2006) Decadal variability of the ENSO tel2econnection to the high-latitude South Pacific governed by coupling with the Southern Annular Mode. J Climate 19:979-997

Gershunov A, Schneider N, Barnett T (2001) Low-frequency modulation of the ENSO-Indian Monsoon rainfall relationship: signal or noise? J Climate 14:2486-2492
Hazeleger W, Severijns C, Haarsma R, Selten F, Sterl A (2003) SPEEDO-model description and validation of a flexible coupled model for climate studies. Technical Report TR-257, KNMI, De Bilt, Netherlands

Hoerling MP, Kumar A, Zhong M (1997) El Niño, La Niña, and the nonlinearity of their teleconnections. J Climate 10:1769-1786, doi: $10.1175 / 1520-0442(1997) 010<1769$ :ENOLNA > 2.0.CO;2

Hoskins BJ, Karoly DJ (1981) The steady linear response of a spherical atmosphere to thermal and orographic forcing. J Atmos Sci 38:1179-1196, doi: 10.1175/15200469(1981)038 < 1179:TSLROA > 2.0.CO;2

Jungclaus JH, Botzet M, Haak H, Keenlyside N, Luo J-J, Latif M, Marotzke J, Mikolajewicz U, Roeckner E (2005) Ocean circulation and tropical variability in the coupled model ECHAM5/MPI-OM. J Climate 19:3952-3972, doi: 10.1175/ JCLI3827.1

Livezey RE, Chen WY (1983) Statistical field significance and its determination by Monte Carlo techniques. Mon Weath Rev 111:46-59

Meehl GA, Teng H, Branstator G (2006) Future changes of El Niño in two coupled climate models. Clim Dyn 26:549-566, doi: 10.1007/s00382-005-0098-0

Molteni F (2003) Atmospheric simulations using a GCM with simplified physical parameterizations. I: model climatology and variability in multi-decadal experiments. Clim Dyn 20:175-191, doi: 10.1007/s00382-002-0268-2

Müller WA, Roeckner E (2006) ENSO impact on midlatitude circulation patterns in future climate change projections. Geophys Res Lett 33:L05711, doi: 10.1029/2005GL025032

Philip S, van Oldenborgh GJ (2006) Shifts in ENSO coupling processes under global warming. Geophys Res Lett 33:L11704, doi:10.1029/2006GL026196

Press WH, Teukolsky SA, Vetterling WT, Flannery BP (1992) Numerical recipes. Cambridge University Press, Cambridge, $933 \mathrm{pp}$

Rayner NA, Parker DE, Horton EB, Folland CK, Alexander LV, Rowell DP, Kent EC, Kaplan A (2003) Global analyses of sea surface temperature, sea ice, and night marine air temperature since the late nineteenth century. J Geophys Res 108(D14):4407, doi: 10.1029/2002JD002670

Selten FM, Branstator GW, Dijkstra HA, Kliphuis M (2004) Tropical origins for recent and future Northern Hemisphere climate change. Geophys Res Lett 31:L21205, doi: 10.1029/ 2004GL020739

Smith TM, Reynolds RW (2003) Extended reconstruction of global sea surface temperatures based on COADS data (1854-1997). J Climate 16:1495-1510

Sterl A, Hazeleger W (2005) The relative roles of tropical and extratropical forcing on atmospheric variability. Geophys Res Lett 32:L18716, doi: 10.1029/2005GL023757

Timm O, Pfeiffer M, Dullo W-C (2005) Nonstationary ENSOprecipitation teleconnection of the equatorial Indian Ocean documented in a coral from the Chagos Archipelago. Geophys Res Lett 32:L02701, doi: 10.1029/2004GL021738

Trenberth KE, Caron JM, Stepaniak DP, Worley S (2002) Evolution of El Niño-Southern Oscillation and global atmospheric surface temperatures. J Geophys Res 107D(8):4065, doi: 10.1029/ 2000JD000298

Uppala SM, Kålberg PW, Simmons AJ, Andrae U, da Costa Bechtold V, Fiorino M, Gibson JK, Haseler J, Hernandez A, Kelly GA, Li X, Onogi K, Saarinen S, Sokka N, Allan RP, Anderson E, Arpe $\mathrm{K}$, Balmaseda MA, Beljaars ACM, van den Berg L, Bidlot J, Borman N, Caires S, Dethof A, Dragosavac M, Fisher M, Fuentes M, Hagemann S, Hólm E, Hoskins BJ, Isaksen L, Janssen PAEM, Jenne R, McNally AP, Mahfouf J-F, Mocrette J- 
J, Rayner NA, Saunders RW, Simon P, Sterl A, Trenberth KE, Untch A, Vasiljevic D, Viterbo P, Woollen J (2005) The ERA-40 re-analysis. Quart J Roy Meteor Soc 131:2961-3012, doi: 10.1256/qj.04.176

Van Oldenborgh GJ, Burgers GJ (2005) Searching for decadal variations in ENSO precipitation teleconnections. Geophys Res Lett 32:L15701, doi: 10.1029/2005GL023110

Van Oldenborgh GJ, Philip SY, Collins M (2005) El Niño in a changing climate: a multi-model study. Ocean Sci 1:81-95, SRef-ID: 1812-0792/os/2005-1-81

Van Ulden AP, van Oldenborgh GJ (2005) Large-scale atmospheric circulation biases and changes in global climate model simula- tions and their importance for regional climate scenarios: a case study for West-Central Europe. Atmos Chem Phys 6:863-881, SRef-ID: 1680-7324/acp/2006-6-863

Walker GT (1925) Correlation in seasonal variations of weather - a further study of world weather. Mon Weath Rev 53:252-254, doi: $10.1175 / 1520-0493(1925) 53<252$ :CISVOW > 2.0.CO; 2

Wang B, An S-I (2001) Why the properties of El Niño changed during the late 1970s. Geophys Res Lett 28:3709-3712

Zelle H, van Oldenborgh GJ, Burgers GJ, Dijkstra H (2005) El Niño and greenhouse warming: Results from ensemble simulations with the NCAR CCSM. J Climate 18:4669-4683 